Revue des patrimoines

$34 \mid 2018$

Lieux de pouvoirs. Architectures administratives dans la France contemporaine, 1945-2013. Avant/Après la décentralisation

\title{
La région Bourgogne : un hôtel de région construit en secteur sauvegardé dans le goût des
}

\section{années 1970}

The 'hôtel de region' of Burgundy, a 1970s building in a designated conservation area

Julien Defillon

\section{(2) OpenEdition}

\section{Journals}

Édition électronique

URL : http://journals.openedition.org/insitu/15993

DOI : 10.4000/insitu. 15993

ISSN : 1630-7305

Éditeur

Ministère de la culture

Référence électronique

Julien Defillon, «La région Bourgogne : un hôtel de région construit en secteur sauvegardé dans le goût des années 1970 », In Situ [En ligne], 34 | 2018, mis en ligne le 04 mai 2018, consulté le 03 mai 2019. URL : http://journals.openedition.org/insitu/15993; DOI : 10.4000/insitu.15993

Ce document a été généré automatiquement le 3 mai 2019.

\section{(c) $(1) \odot$}

In Situ Revues des patrimoines est mis à disposition selon les termes de la licence Creative Commons Attribution - Pas d'Utilisation Commerciale - Pas de Modification 4.0 International. 


\title{
La région Bourgogne : un hôtel de région construit en secteur sauvegardé dans le goût des années 1970
}

\author{
The 'hôtel de region' of Burgundy, a 1970s building in a designated conservation \\ area
}

Julien Defillon

1 Par acte notarié en date des 8 et 19 juillet 2013, le conseil régional de Bourgogne est devenu propriétaire de l'hôtel de région' ${ }^{1}$. Afin de mieux connaître l'histoire du bâtiment et d'en apprécier la valeur patrimoniale, la collectivité a lancé en 2014 une étude monographique confiée à la direction culture et patrimoine, sports et jeunesse - service patrimoine et inventaire.

Reconstituée à partir du fonds de l'architecte Roger Martin Barade, conservé aux Archives départementales de la Côte-d'Or'r l'histoire de l'édifice, depuis les premiers projets jusqu'à son achèvement, a mis en lumière le rôle des Bâtiments de France et de la Commission Supérieure des Monuments Historiques (CSMH) dans les changements radicaux apportés au programme architectural. En effet, l'emplacement du terrain choisi, en limite du secteur sauvegardé du Vieux-Dijon, et la proximité immédiate du Cellier de Clairvaux ${ }^{3}$, classé au titre des Monuments historiques, peuvent être considérés comme des « contraintes patrimoniales ». Cette étude monographique centre son analyse sur les conditions d'édification du bâtiment, puis sur l'attention portée à l'aménagement intérieur, dont l'approche est tout à fait représentative de la pratique architecturale liée aux bâtiments administratifs en France dans les années 1960-1970. Les architectes ont fait appel à plusieurs artistes contemporains renommés, démontrant ainsi leur volonté de faire des espaces de réception et d'accueil des lieux particulièrement soignés avec un décor à la fois moderne et digne de la nouvelle institution. La bonne conservation de ces éléments s'avère alors déterminante pour l'analyse patrimoniale de l'édifice, qui offre 
également un témoignage du goût en matière d'ornement pour l'architecture de l'administration à la fin des années 1970 en France.

\section{Historique et conditions d'édification}

Les ébauches de ce nouvel échelon territorial que sont les régions apparaissent avec la création des circonscriptions d'action régionale en 1960. Mais c'est avec la loi du 5 juillet 1972 que sont véritablement créées ces nouvelles institutions, qui prennent alors le nom d'Établissement Public Régional (EPR). L'instauration de nouveaux services administratifs entraîne la réalisation de locaux pour accueillir les agents. En partie déjà étudiée ${ }^{4}$, la genèse des premiers hôtels de région expose les différents choix opérés en matière de création architecturale, qu'il est possible de synthétiser en trois groupes. Le premier rassemble les institutions ayant opté pour la reconversion d'un édifice ancien ${ }^{5}$, choix qu'il faut sans doute analyser comme une tentative de légitimer la nouvelle collectivité en l'ancrant dans un édifice patrimonial. Le deuxième regroupe les régions qui ont fait le choix de la création d'un nouveau bâtiment, plus fréquemment adoptée dans la moitié sud de l'Hexagone ${ }^{6}$. Quant au troisième cas, il s'agit des régions qui ont acquis différents bâtiments, anciens immeubles de logements ou de bureaux, et les ont adaptés progressivement à leurs besoins? .

Cette première phase dans la construction des hôtels de région démarre dans quelques cas avant le vote des lois Defferre de 1982, comme en Bourgogne. Mais si le bâtiment actuel s'avère au final un des premiers hôtels de région programmés en France, il convient de rappeler que les origines du projet sont davantage dues à la convergence de différents facteurs, comme la volonté du Département et de la préfecture d'agrandir leurs propres locaux. « Nouvel immeuble départemental », « nouvelle préfecture »..., ce sont en effet les premiers termes mentionnés dans les documents pour évoquer le projet du futur bâtiment. Ces dénominations provisoires rappellent bien que l'édifice devait également héberger la préfecture de région ainsi que le Comité économique et social régional (CESR) 8 .

\section{Le lancement du programme et les premiers projets}

Après la création des EPR en 1972, c'est le conseil général de la Côte-d'Or qui est chargé de lancer la construction d'un nouveau bâtiment. En conséquence, le Département valide en sa séance du 28 juin 1974 le projet de construction d'un édifice, qui doit non seulement accueillir les services de l'EPR mais aussi, entre autres, les locaux du CESR et de la préfecture de région. 


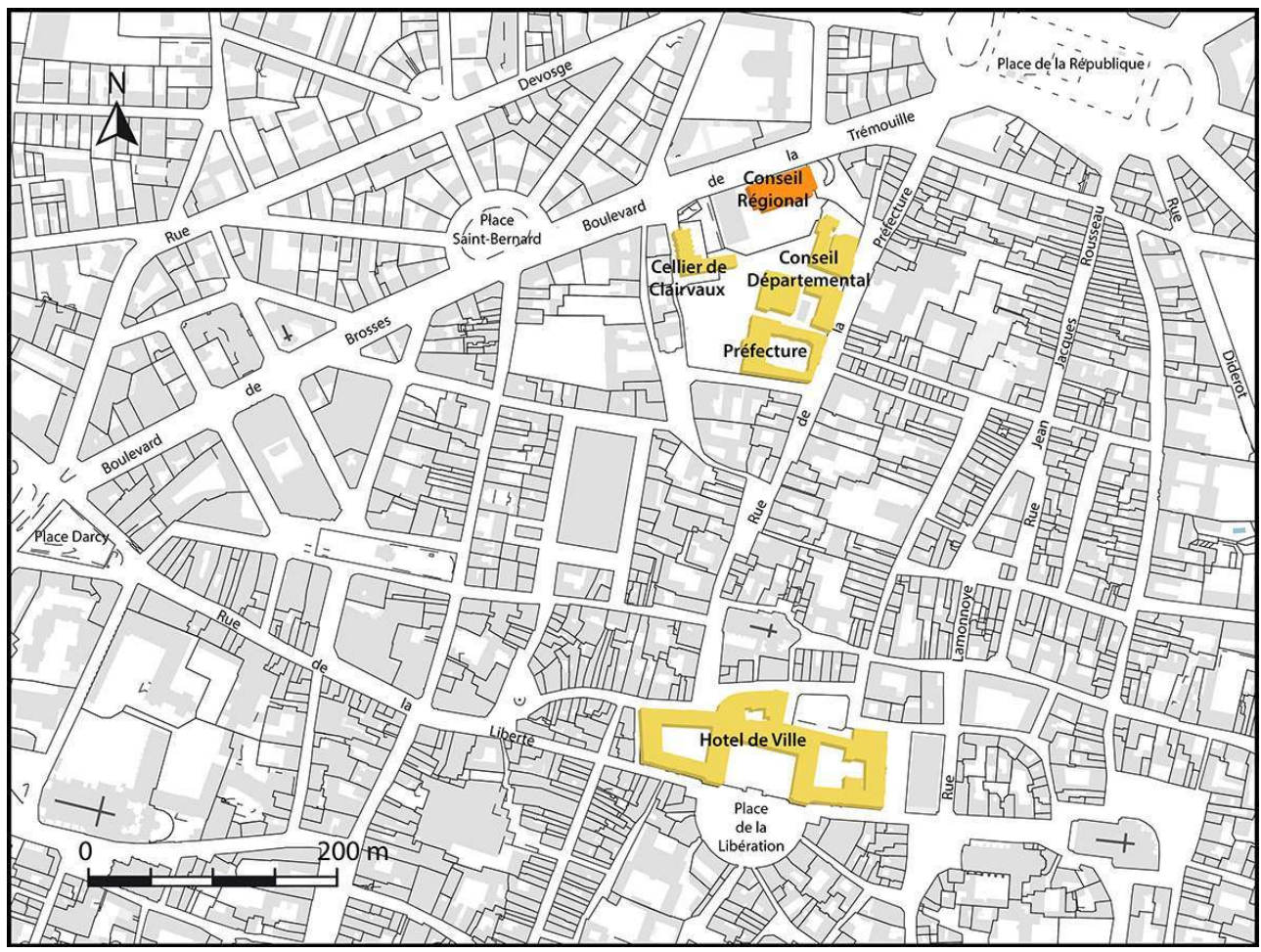

Plan de situation

Aut. Mathias Papigny. (C) Région Bourgogne-Franche-Comté, Inventaire du patrimoine, ADAGP, 2017.

6 Le site retenu appartient déjà au conseil général (fig. 1); il s'agit d'un espace vierge utilisé à l'époque comme parking (fig. 2, fig. 3). Délimité par les rues de Clairvaux, Joseph-Magnin et James-Demontry, il était auparavant loti de deux îlots mêlant habitations et entrepôts qui jouxtaient le Cellier de Clairvaux. Ce dernier étant protégé depuis 1915, c'est le seul bâtiment conservé après la démolition des constructions disparates, entre 1967 et 1968. 
Figure 2

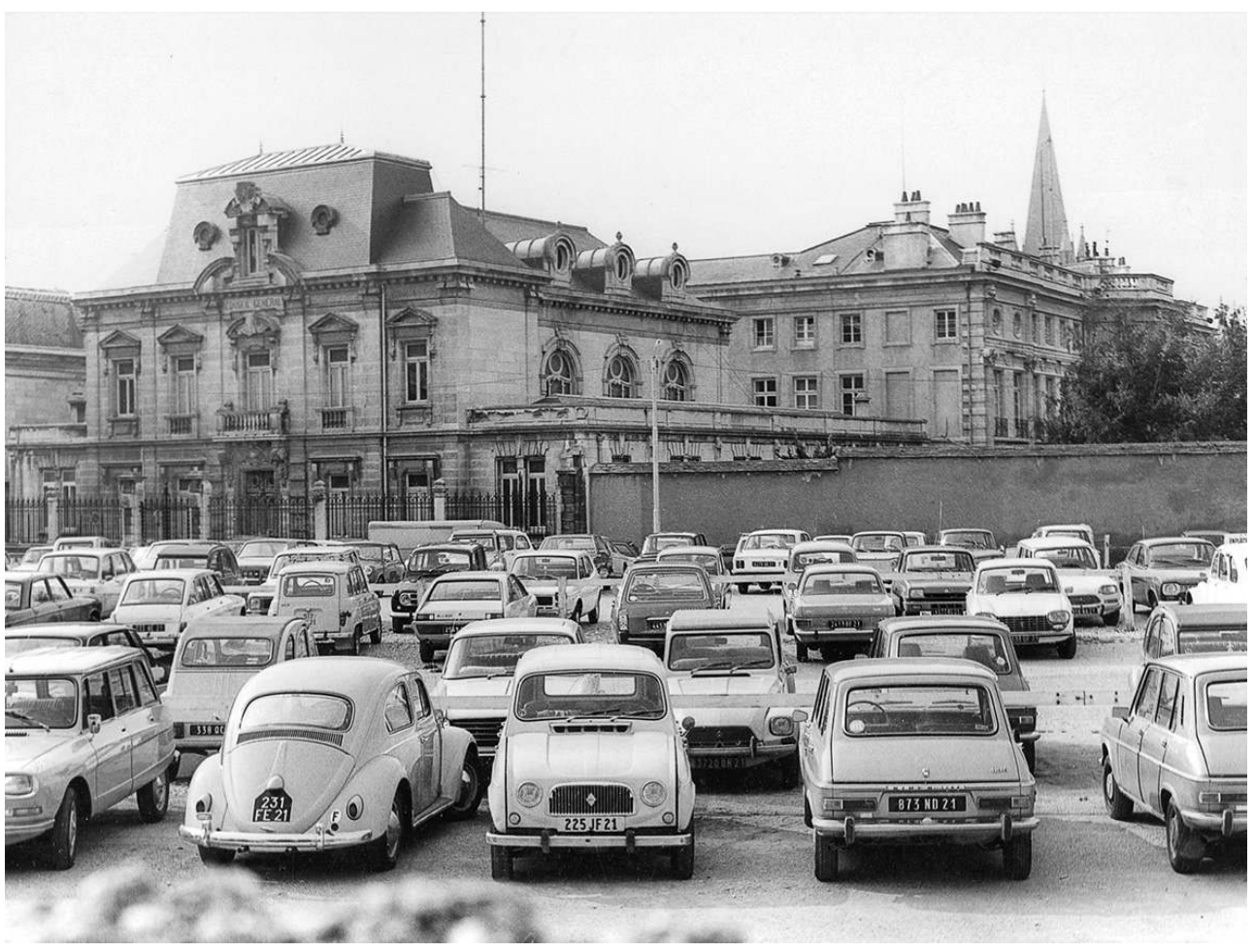

Ancien parking le long du boulevard de la Trémouille, août 1975.

Repro. Frédéric Petot. Archives départementales de la Côte-d'Or, 32 J 48. @ CG21/F.Petot/2014, réutilisation soumise à conditions. 


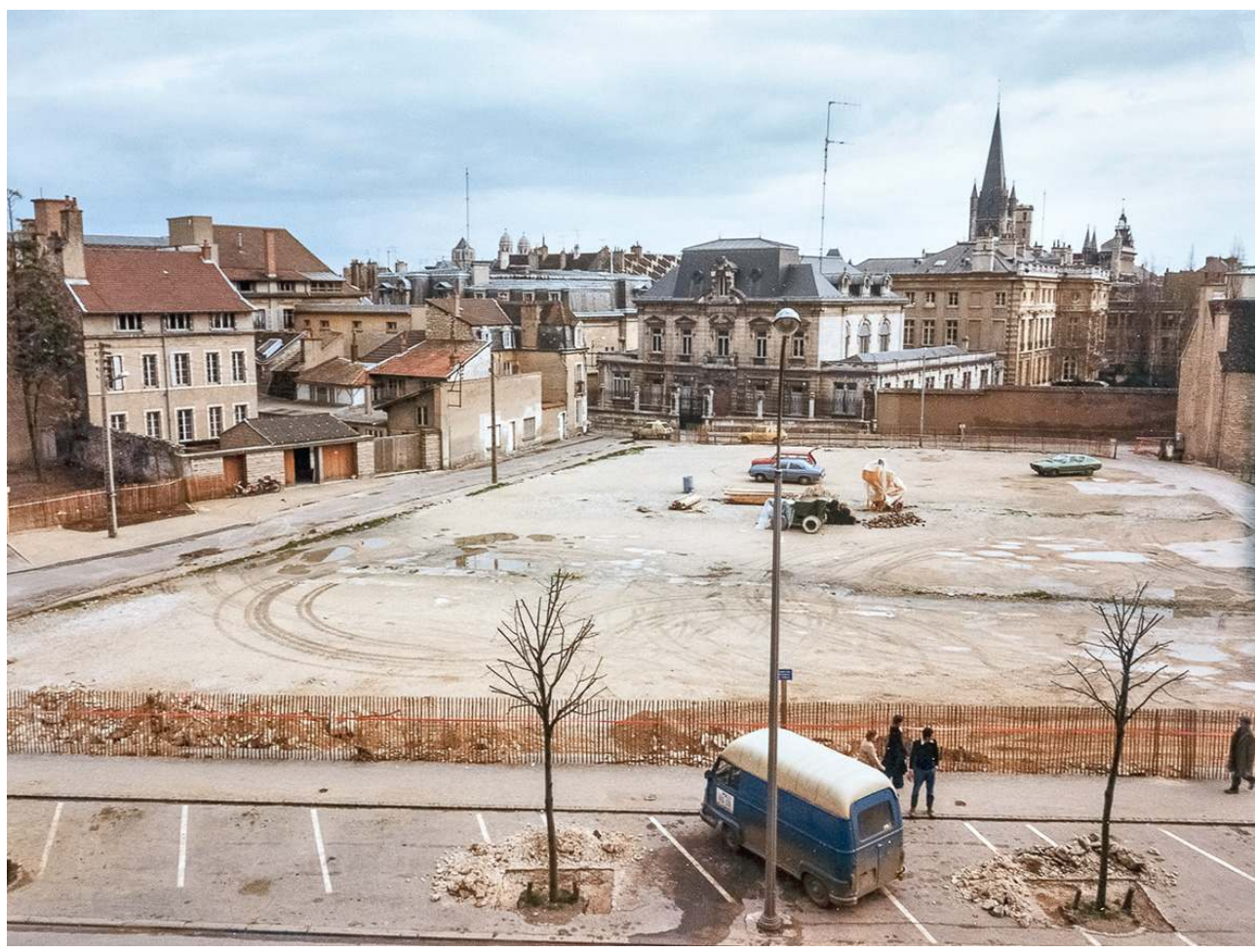

Vue du chantier en mars 1977 : terrain avant travaux.

Repro. Pierre-Marie Barbe-Richaud. Archives départementales de la Côte-d'Or, 32 J 57, réutilisation soumise à conditions. (C) Service Patrimoine et inventaire, Région Bourgogne, 2014.

Une commission spéciale est créée pour suivre l'avancement des projets, placée sous l'autorité du préfet de région. La Ville est invitée à participer à ces réunions pour plusieurs raisons. Dans un premier temps, il s'agit d'obtenir son accord pour le déclassement des rues car le projet de ce nouvel immeuble inclut la création et la disparition de certains tracés. Le second point, sur lequel plusieurs membres de la commission souhaitent obtenir l'avis et la participation de la mairie, concerne la création d'un parking souterrain sous le futur bâtiment.

8 Afin de pallier la suppression du parking en plein-air, le conseil général envisage l'ajout d'un parc de stationnement souterrain. Cette partie du projet est validée dès le mois d'avril $1975^{\circ}$, attendu qu'un parking public à proximité du centre-ville constituerait autant un atout pour la ville qu'un moyen de rentabiliser en partie l'édification du futur immeuble.

9 La municipalité dijonnaise accepte de participer aux discussions sur le projet et sa première demande est que le parking ne soit pas réservé uniquement aux agents territoriaux. Les échanges suivants portent sur le nombre de niveaux du parking ouverts au public, l'installation de parcmètres en surface autour du futur bâtiment et sur le tracé des abords.

C'est Roger-Martin Barade ${ }^{10}$ qui, en tant qu'architecte du département, est chargé de réaliser le nouvel immeuble avec son associé François Ruault ${ }^{11}$. La consultation du fonds Barade révèle qu'en 1962 l'architecte avait déjà travaillé sur un projet d'extension des services de la préfecture sur le même emplacement. Aucune autre donnée ne permet de connaître le contexte d'origine de cet agrandissement des bâtiments qui se composait 
d'un vaste immeuble sur pilotis perpendiculaire au boulevard de la Trémouille, et d'un autre, de moindre hauteur, placé, lui, dans l'alignement de la voirie. L'architecte a sans doute en tête cette ancienne proposition lorsqu'il travaille avec son associé F. Ruault au nouveau projet de l'immeuble départemental. En effet, dans les premiers plans qu'ils livrent en 1975 (fig. 4, 5, 6), on constate la reprise de cet axe perpendiculaire au boulevard de la Trémouille, ainsi que la création d'une nouvelle perspective donnant sur la façade principale de l'immeuble du conseil général.

\section{Figure 4}

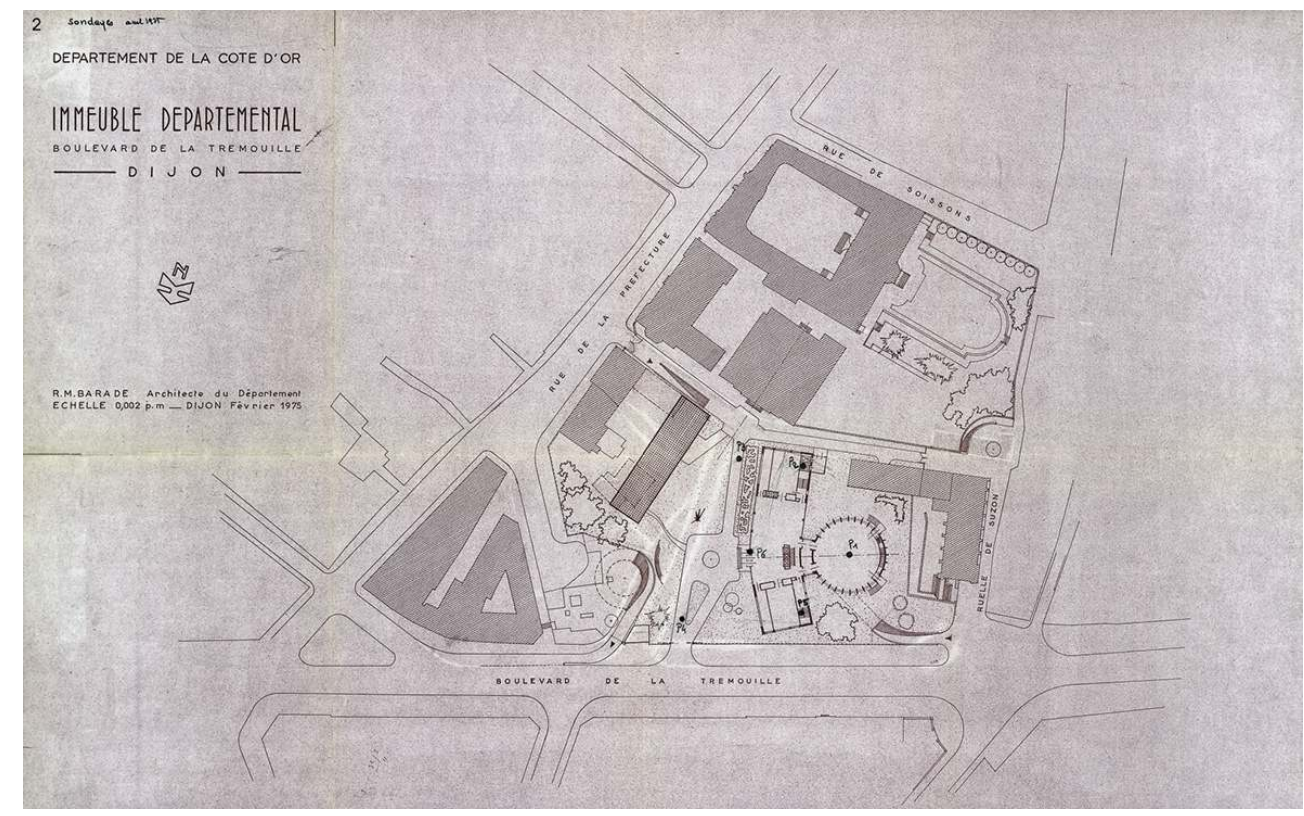

Roger-Martin Barade, immeuble départemental boulevard de la Trémouille, plan de masse et du rezde-chaussée, février 1975.

Repro. Frédéric Petot. Archives départementales de la Côte-d'Or, 32 J 48. @ CG21/F.Petot/2014, réutilisation soumise à conditions. 
Figure 5

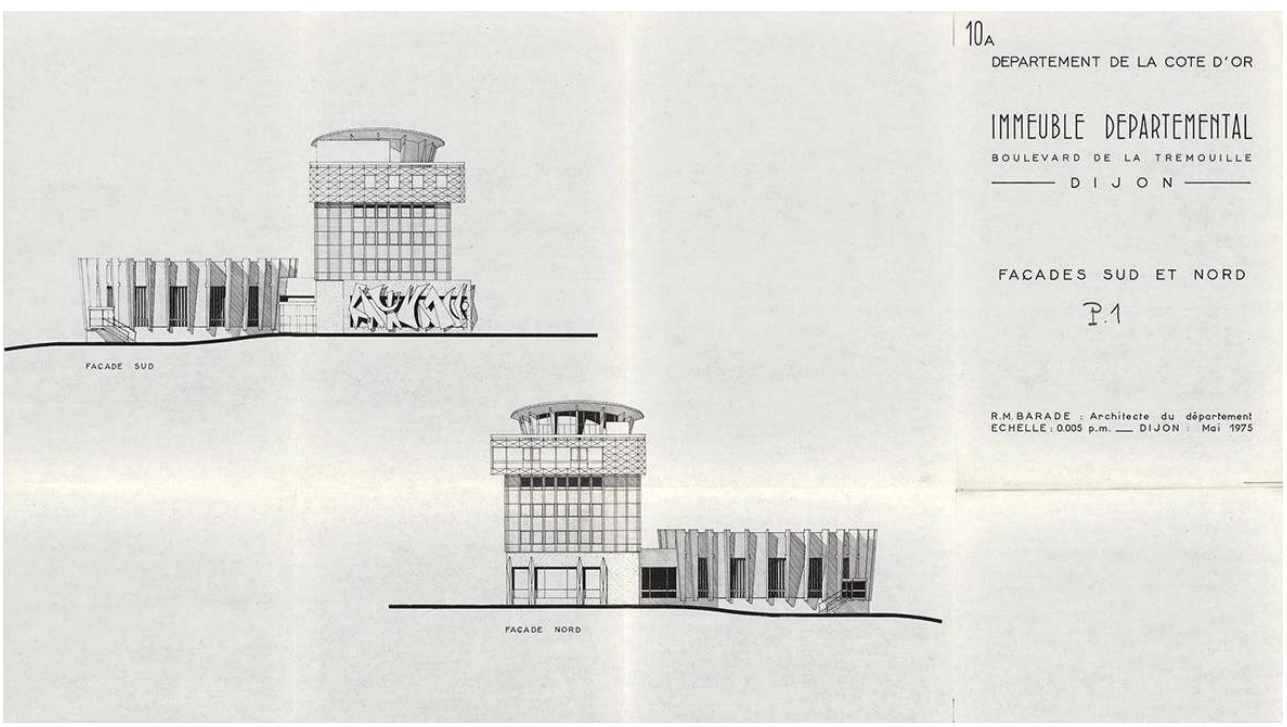

Roger-Martin Barade, Immeuble départemental boulevard de la Trémouille, façades sud et nord, mai 1975.

Repro. Frédéric Petot. Archives départementales de la Côte-d'Or, 32 J 49. (C) CG21/F.Petot/2014, réutilisation soumise à conditions.

Figure 6

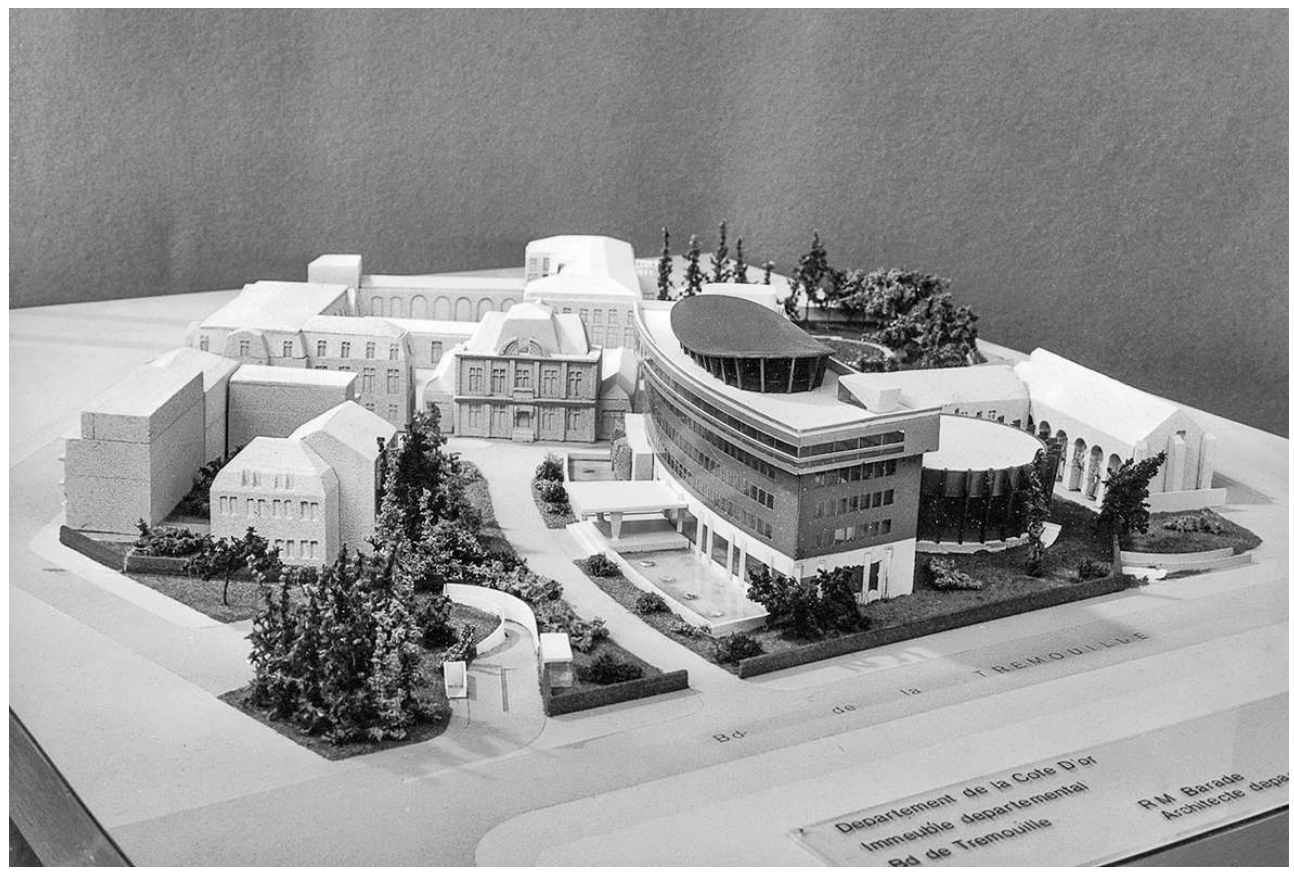

Photographie de la maquette du premier projet, 1975.

Repro. Frédéric Petot. Archives départementales de la Côte-d'Or, 32 J 49. ( C CG21/F.Petot/2014, réutilisation soumise à conditions.

11 Le nouveau bâtiment, qui présente une courbe pour accentuer l'effet de perspective, reprend le vocabulaire usuel d'un immeuble administratif des années 1970 avec une volonté de créer une architecture à la fois solennelle et imposante. Un vaste perron couvert par un auvent introduit le niveau de rez-de-chaussée largement vitré tandis que 
les trois niveaux suivants, avec mur-rideau, présentent un alignement de baies standard. Afin d'animer davantage la façade, l'avant-dernier étage comporte un léger surplomb avec un traitement différent pour le bardage. Il est couvert par une toiture-terrasse à laquelle s'ajoute un volume de plan elliptique avec une toiture incurvée, prévu pour accueillir une cafétéria et des espaces techniques. Cette partie sommitale du bâtiment est cernée par une série de lames de béton qui soutient les avancées de la toiture. Des lames identiques sont reprises sur les parois de la vaste salle circulaire au rez-de-chaussée. Située à l'arrière de l'immeuble, elle doit servir de salle de réunion et est prévue pour accueillir jusqu'à 400 places. Au sous-sol se trouve le parking avec des accès différenciés pour les niveaux réservés aux agents territoriaux et ceux pour le public.

R.-M. Barade et F. Ruault ont également imaginé une variante à ce projet. Si le parti pris d'implantation reste identique, le bâtiment principal reçoit quelques modifications avec un travail plus élaboré sur les décrochements et les variations de volumes (fig. 7). Dans les deux cas, les architectes ont proposé la possibilité de construire un second immeuble, strictement fonctionnel et plus simple dans son traitement architectural, de l'autre côté de la nouvelle rue.

Figure 7

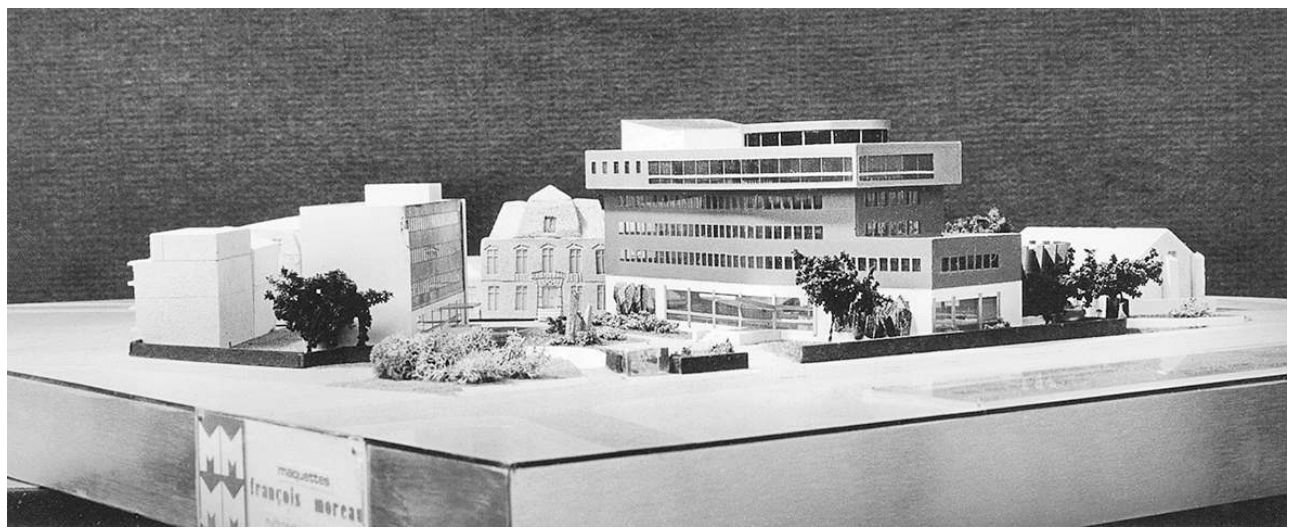

Photographie de la maquette de la variante du premier projet, 1975.

Repro. Frédéric Petot. Archives départementales de la Côte-d'Or, 32 J 49. @ CG21/F.Petot/2014 réutilisation soumise à conditions.

\section{Le rôle de l'État et la place de l'architecture contemporaine en site historique}

Bien qu'ils soient représentatifs de la création architecturale de cette époque, les premiers plans et élévations de façade de R.-M. Barade et F. Ruault ne suscitent pas un grand enthousiasme de la part des différents chefs de projet. Ce sont justement l'aspect massif et imposant du bâtiment, ainsi que la salle ronde, qui amènent le plus de réserves. Lors de la réunion de présentation de la maquette, le 12 juin 1975, l'Architecte des Bâtiments de France (ABF), Jean-Michel Marouzé, critique le plan de masse de ce nouvel aménagement, notamment à cause de la disposition du futur bâtiment qui, en tournant le dos au Cellier de Clairvaux, "annule l'agrément des abords du Cellier " ${ }^{12}$. Il propose de soumettre le projet à la Commission des Abords (CA), ce qui n'est d'ailleurs pas sans soulever les objections de quelques conseillers généraux ainsi que du préfet lui-même. Ils s'inquiètent du retard que pourrait prendre le projet s'il devait attendre l'aval du 
ministère de la Culture. La forme de la salle de conférences fait elle aussi débat, certains estimant qu'elle s'inscrit «mal dans le cadre urbain de la ville de Dijon » ${ }^{13}$. À la suite d'une autre réunion, le 5 août 1975, le principe d'une présentation du projet devant la CA est acté. Mais l'architecture de l'immeuble ne semble pas pouvoir recueillir un avis favorable de la part de ses membres; R.-M. Barade est alors prié de réfléchir à une variante susceptible de convenir non seulement à la $\mathrm{CA}$, mais également aux différentes personnes chargées localement de l'exécution du projet (fig. 8, fig. 9).

Figure 8

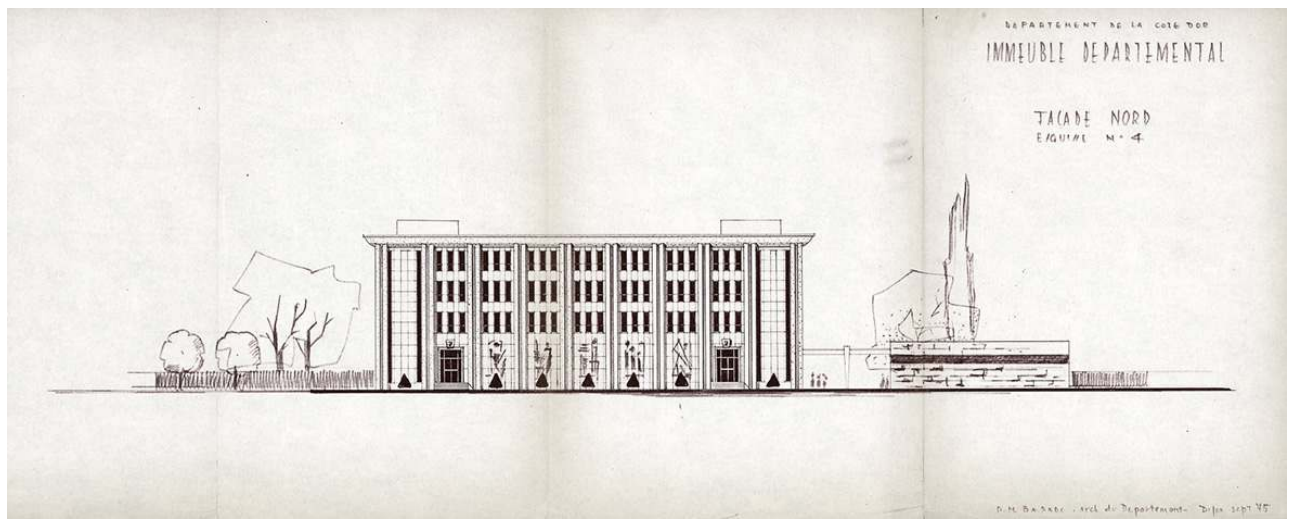

Roger-Martin Barade : second projet, esquisse de la façade principale (nord), septembre 1975. Repro. Frédéric Petot. Archives départementales de la Côte-d'Or, 32 J 50. @ C C 21/F.Petot/2014, réutilisation soumise à conditions.

Figure 9

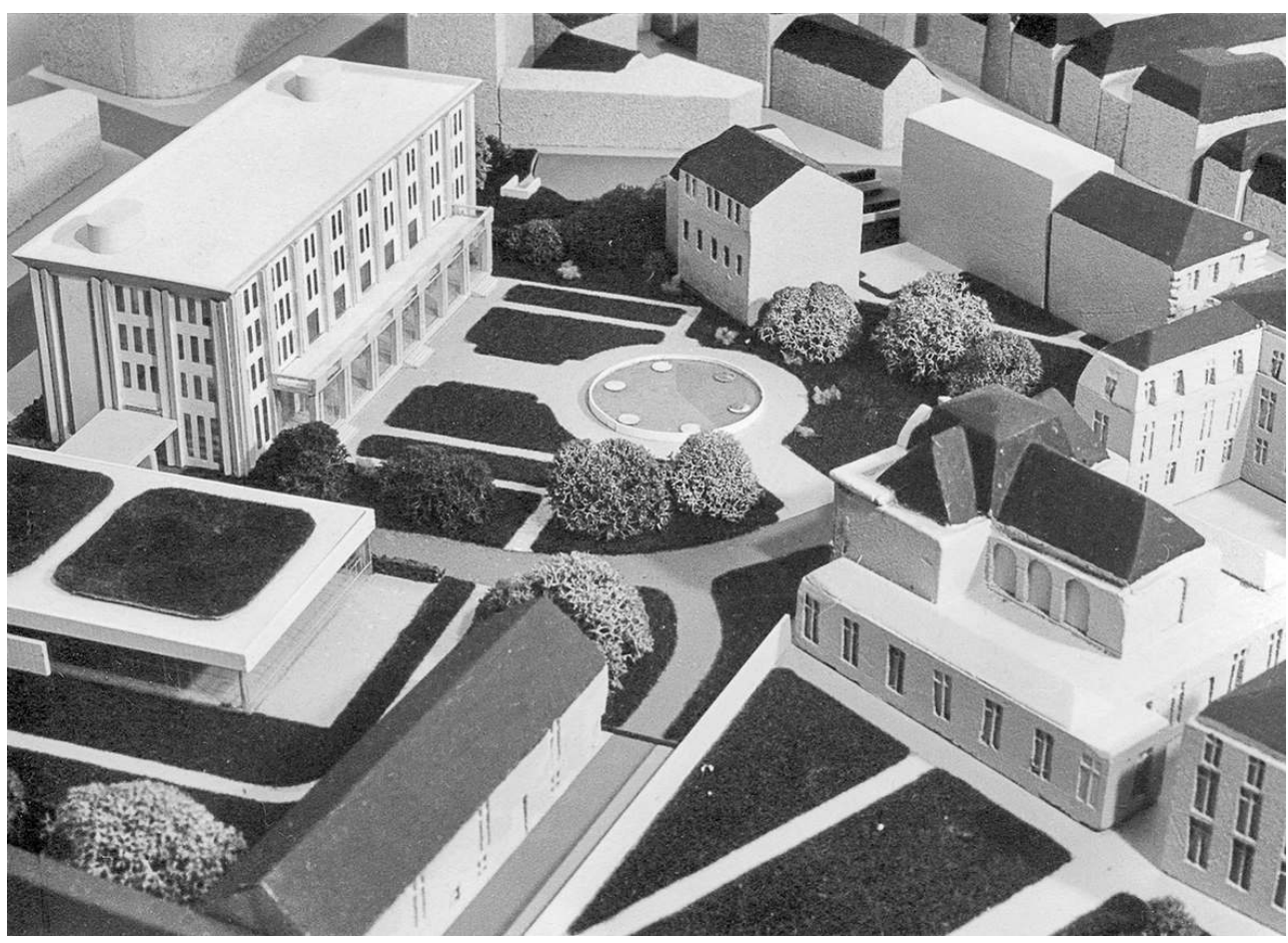

Photographie de la maquette du second projet, vue sur la façade arrière.

Repro. Frédéric Petot. Archives départementales de la Côte-d'Or, 32 J 50. ㄷ CG21/F.Petot/2014, réutilisation soumise à conditions. 
La présentation des deux projets à la $\mathrm{CA}^{14}$ a finalement lieu le $1^{\mathrm{er}}$ octobre 1975 . C'est à nouveau la monumentalité de l'édifice qui motive les critiques sur la première version imaginée. Outre la hauteur du bâtiment, il lui est également reproché de présenter un «caractère composite de l'architecture [qui] manifeste une certaine agressivité au voisinage du Cellier de Clairvaux $»^{15}$. Si la première solution proposée est jugée « inacceptable parce qu'elle ne tient aucun compte de l'environnement », la seconde est en revanche appréciée, notamment pour l'effort d'intégration au site en diminuant les masses bâties (fig. 10) ainsi que pour les espaces libres et plantés qui mettent davantage en valeur le bâti ancien. En revanche, le dessin de la façade est jugé comme "un témoignage peu convaincant de l'architecture moderne » selon le maire de Dijon. La CA invite en conclusion à une étude plus poussée sur l'architecture du futur immeuble, soulignant « l'exigence de qualité » qu'il appelle.

Figure 10

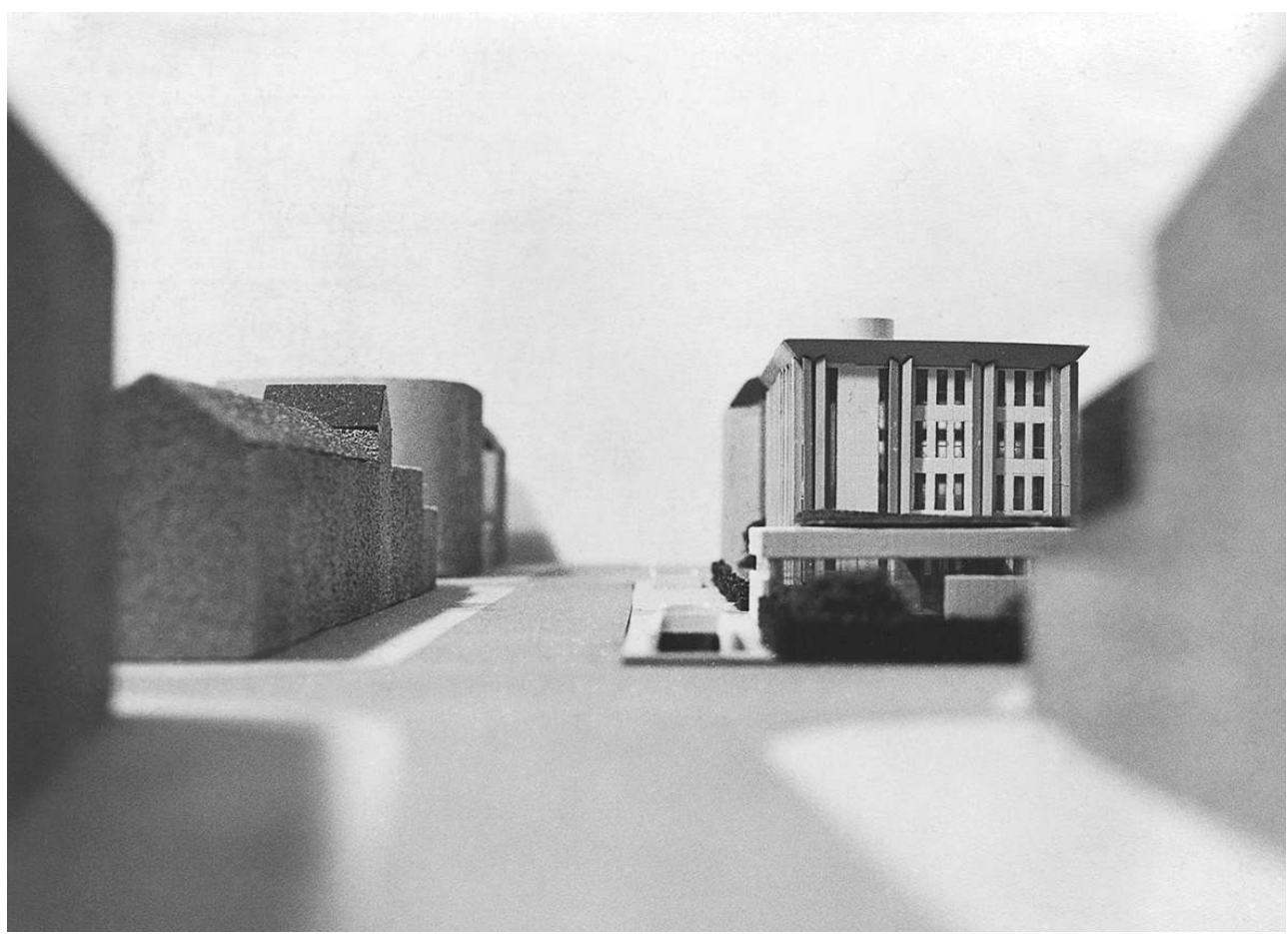

Photographie de la maquette du second projet, vue de l'implantation depuis le boulevard de la Trémouille.

Repro. Frédéric Petot. Archives départementales de la Côte-d'Or, 32 J 50. @ CG21/F.Petot/2014 réutilisation soumise à conditions.

Ce dernier point permet d'appréhender le rôle de la CA et le sens qu'elle cherche à donner à ses observations, mais également la manière dont sont envisagées les constructions contemporaines au sein des sites anciens et patrimoniaux afin de comprendre comment les architectes ont orienté leur approche créative. Cette question de l'insertion d'une architecture contemporaine en centre historique avait déjà suscité des débats et plusieurs réponses avant la création de la section des Abords au sein de la CSMH. Dès la fin du XIX siècle, Camillo Sitte traite des liens entre l'objet patrimonial bâti et son environnement urbain immédiat ${ }^{16}$. Ses théories sur le lien historique et fonctionnel entre l'objet patrimonial et son cadre sont par la suite décriées par une partie des architectes et urbanistes du mouvement Moderne ${ }^{17}$. Dans La Charte d'Athènes, Le Corbusier condamne 
fermement toute tentative d'une architecture d'imitation : «Copier servilement le passé, c'est se condamner au mensonge, c'est ériger le faux en principe [...]. En mêlant le faux au vrai, [...] on n'aboutit qu'à une reconstruction factice juste capable de jeter le discrédit sur les témoignages authentiques qu'on avait le plus à cœur de préserver. $»^{18}$ Mais le texte issu du IV ${ }^{e}$ Congrès International d'Architecture Moderne (CIAM) se livre davantage à une dénonciation des créations pastichant les styles historiques, qu'à une véritable réflexion sur la place de l'architecture contemporaine dans des ensembles anciens.

Entre-temps, la Charte d'Athènes pour la restauration des Monuments historiques, adoptée suite à la conférence éponyme de 1931, avait déjà attiré l'attention sur la question des abords en arguant l'importance de "respecter, dans la construction des édifices, le caractère et la physionomie des villes, surtout dans le voisinage des monuments anciens dont l'entourage doit être l'objet de soins particuliers $»^{19}$. Il faut ensuite attendre la loi du 25 février 1943 pour qu'une première attention officielle soit accordée aux abords des Monuments historiques avec l'instauration du périmètre des 500 mètres autour de tout édifice protégé ${ }^{20}$.

Lorsqu'elle est créée en 1964, le rôle de la CA est de veiller à la préservation des périmètres de protection autour du patrimoine bâti et urbain protégé. Néanmoins, il serait inexact de voir la CA comme une instance opposée à toute forme de contemporanéité. Son objectif est au contraire d'inciter et de promouvoir l'architecture contemporaine tout en veillant au respect de la trame urbaine préexistante et du bâti ancien. Comme l'expliquent Xavier Laurent et Isabelle Backouche, sa composition « traduit très bien la volonté de la direction de l'Architecture de tenter la synthèse entre le passé et le présent $"^{21}$. Avec sa création en tant que $2^{\mathrm{e}}$ section de la CSMH, la CA devient ainsi «un outil au service d'une politique de l'architecture ${ }^{22}$. Le souhait de Max Querrien ${ }^{23}$ est $d^{\prime}$ ' utiliser la création architecturale comme outil pour mettre en valeur l'espace, le monument étant considéré comme une incitation ${ }^{24}$.

Mais l'année 1975 correspond également à l'arrivée de Michel Guy aux Affaires

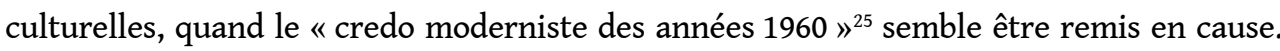
Une nouvelle génération davantage post-moderne remplace ainsi progressivement les anciens tenants d'un fonctionnalisme pur hérité de la Modernité. Même si l'effet n'est pas de masse, on constate également que les historiens et historiens de l'art deviennent peu à peu majoritaires au sein de la CA, remplaçant ainsi quelques architectes de l'école moderniste. Une importance croissante est alors donnée au travail sur l'insertion et l'harmonisation avec le patrimoine urbain environnant, concept qui se développe à la même époque. Au demeurant, une attention est toujours portée à la qualité architecturale de l'édifice projeté, comme en témoignent les remarques faites aux premières esquisses de R.-M. Barade et F. Ruault sur leur second projet.

Cette nouvelle approche s'observe également à l'échelle mondiale. En effet, à l'occasion de la $3^{\mathrm{e}}$ assemblée générale de l'ICOMOS à Budapest du 25 au 30 juin 1972, un colloque international est organisé par l'institution portant sur «l'intégration de l'architecture contemporaine dans les ensembles anciens ». À la suite de cet événement, l'ICOMOS adopte plusieurs conclusions, dont le respect du tissu urbain préexistant, tout en reconnaissant le besoin pour la ville de se reconstruire sur elle-même. C'est en partie d'Italie que vient cette nouvelle approche de la construction en centre urbain : les idées du mouvement "La Tendenza », dans les années $1960^{26}$, font progressivement émerger en France le principe d'un retour à la ville historique et l'acceptation de l'héritage de l'histoire dans l'espace de la cité. Ainsi, les premiers projets de R.-M. Barade et F. Ruault 
et les encouragements à travailler davantage sur l'insertion urbaine (demande de respect des hauteurs, d'établir l'alignement en accord avec les constructions préexistantes, de laisser une visibilité au Cellier de Clairvaux, etc.) sont à analyser comme une conséquence de cette approche nouvelle de la construction contemporaine en centre ancien.

\section{Architecture et insertion urbaine}

Suite à la validation de principe du second projet, les architectes s'attachent à suivre les recommandations de la CA et à retravailler la composition des façades. En outre, afin de respecter les limitations en hauteur, il est décidé de réaliser un second bâtiment pour abriter le restaurant administratif. Cette construction rectangulaire et de faible hauteur a conservé l'implantation perpendiculaire des anciens projets pour libérer au maximum la vue sur le Cellier de Clairvaux. R.-M. Barade demande alors conseil à son collègue Henry Bernard qui lui suggère d'affirmer davantage le caractère de l'institution tout en conservant des volumes simples ${ }^{27}$.

Figure 11

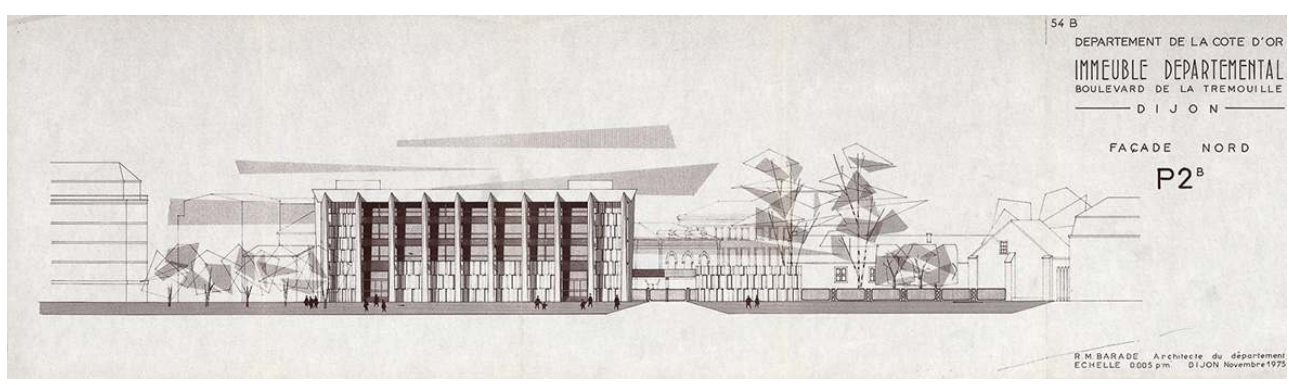

Roger-Martin Barade : second projet, proposition de façade 2B, novembre 1975.

Repro. Frédéric Petot. Archives départementales de la Côte-d'Or, 32 J 50. (c) CG21/F.Petot/2014, réutilisation soumise à conditions.

Figure 12

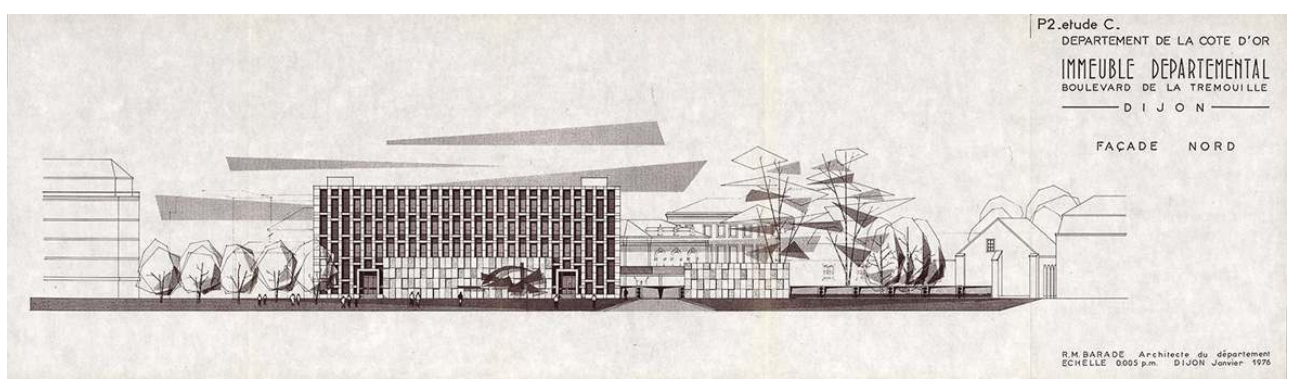

Roger-Martin Barade : second projet, proposition de façade 2C, janvier 1976.

Repro. Frédéric Petot. Archives départementales de la Côte-d'Or, 32 J 50. @ CG21/F.Petot/2014, réutilisation soumise à conditions. 
Figure 13

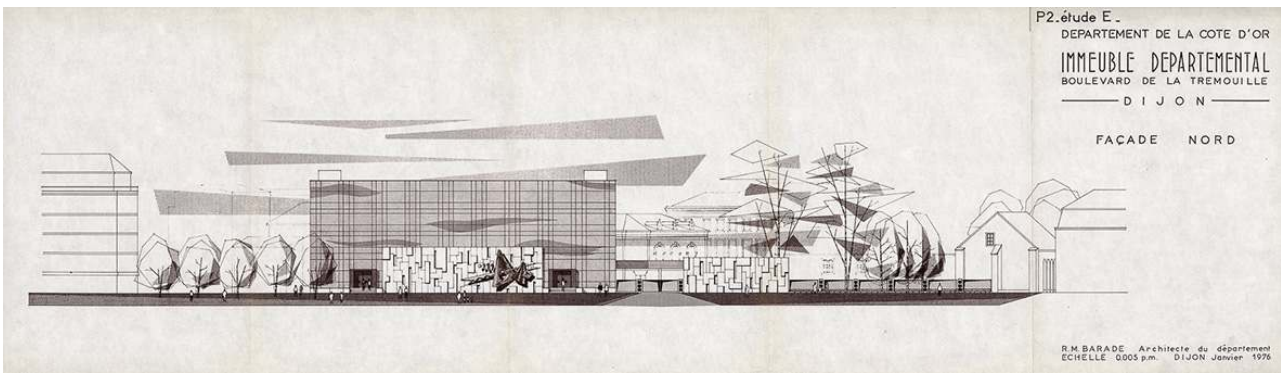

Roger-Martin Barade : second projet, proposition de façade 2E, janvier 1976.

Repro. Frédéric Petot. Archives départementales de la Côte-d'Or, 32 J 50. (c) CG21/F.Petot/2014,

réutilisation soumise à conditions.

Figure 14

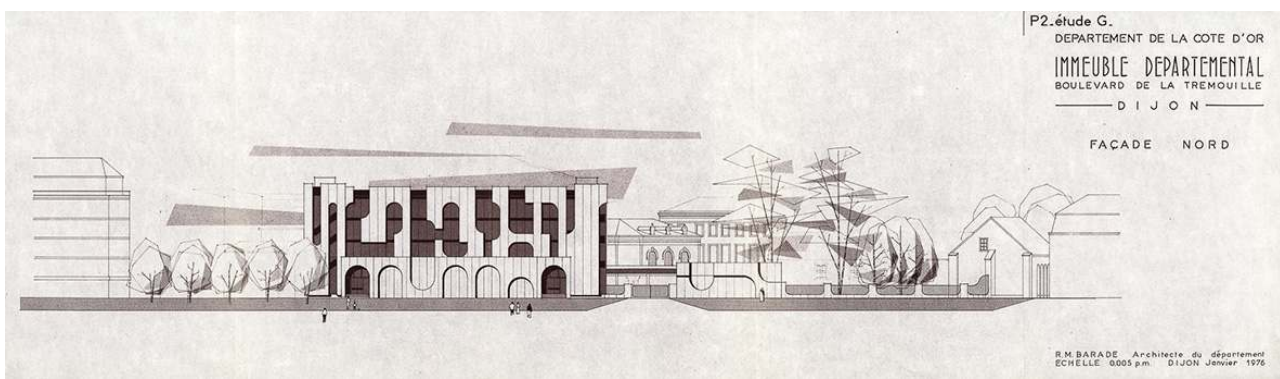

Roger-Martin Barade : second projet, proposition de façade 2G, janvier 1976.

Repro. Frédéric Petot. Archives départementales de la Côte-d'Or, 32 J 50. @ C CG21/F.Petot/2014, réutilisation soumise à conditions.

Ce ne sont pas moins de sept propositions de façade, réalisées entre novembre 1975 et janvier 1976, que les architectes vont présenter (fig. 11, 12, 13, 14). Toutes se caractérisent par une tentative d'animer en façade un volume général extrêmement simple : le parallélépipède rectangle. Dans la solution adoptée (fig. 15), les architectes ont réalisé un travail de composition et d'harmonisation sur les lignes verticales et horizontales.

\section{Figure 15}

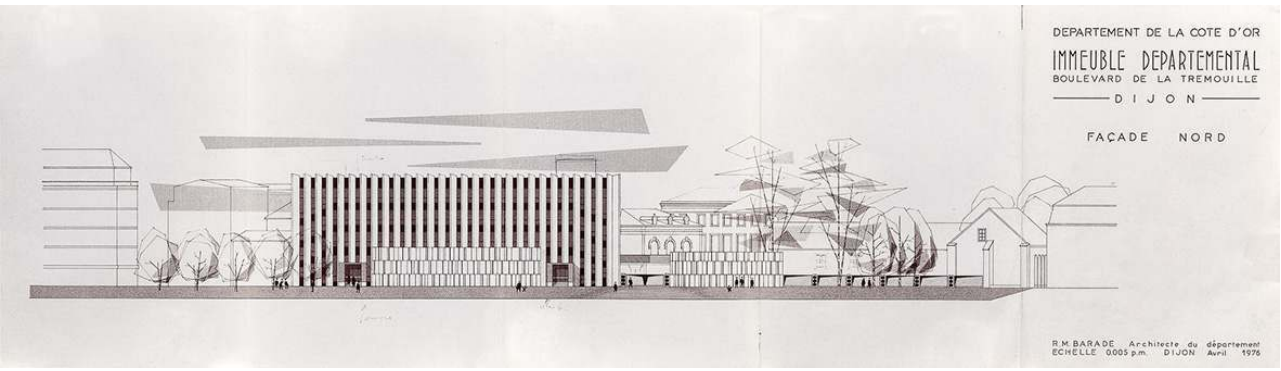

Roger-Martin Barade : second projet, élévation finale de la façade principale, avril 1976.

Repro. Pierre-Marie Barbe-Richaud. Archives départementales de la Côte d'Or, 32 J 50. @ Service Patrimoine et inventaire, Région Bourgogne, 2014

$\mathrm{Au}$ format rectangulaire de l'ensemble, répété par le parement en béton avec revêtement en pierre matérialisant la salle des Assemblées du premier niveau, répond la scansion 
verticale des lames de béton saillantes. Tempérant les masses horizontales et dirigeant le regard vers le haut, ces lignes verticales accroissent la monumentalité de l'ensemble malgré les limites de hauteur qui étaient imposées. Leur disposition en biais offre également un effet dynamique à l'ensemble de la façade dont la perception et l'alternance ouverture/fermeture varie en fonction de la position du spectateur (fig. 16).

Figure 16

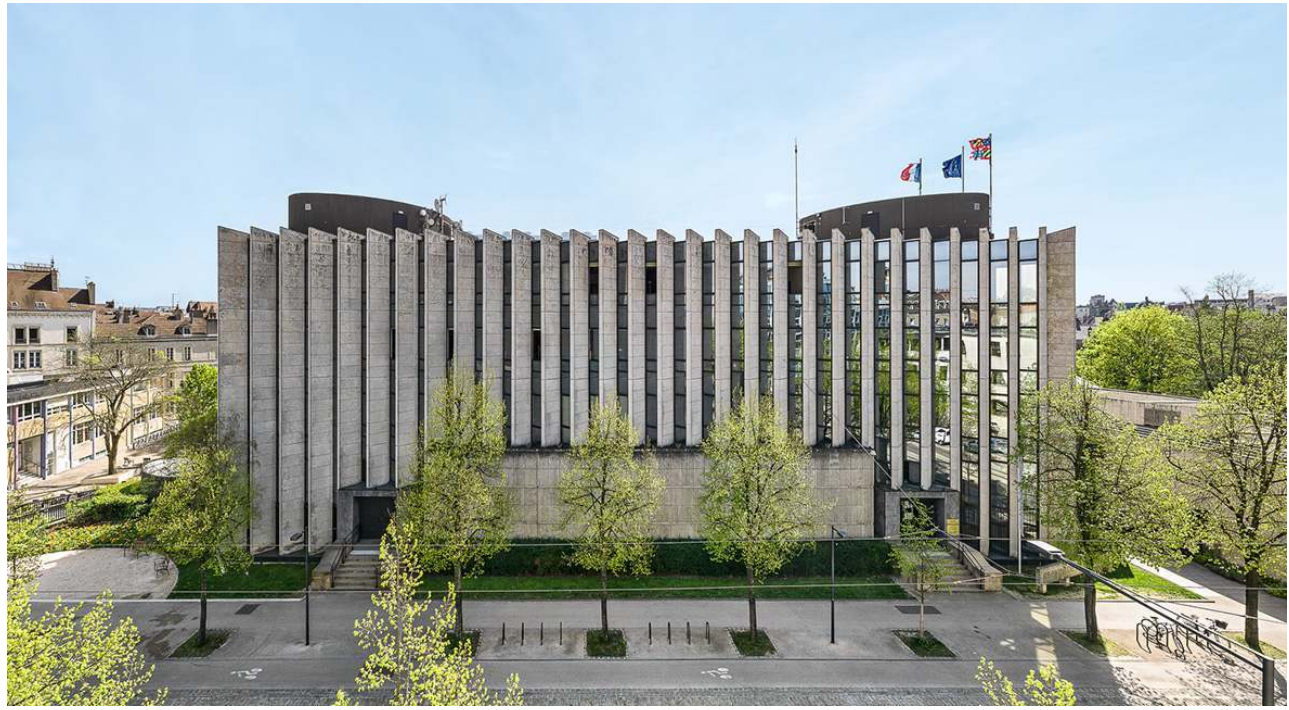

Hôtel de région : façade antérieure.

Phot. Pierre-Marie Barbe-Richaud. (c) Service Patrimoine et inventaire, Région Bourgogne, 2014.

Enfin, l'aspect géométrique du bâtiment est encore renforcé par le format carré des deux portes d'entrée (fig. 17). Devant modifier les portes vitrées du projet d'origine suite à de nouvelles normes en matière de sécurité, les architectes font appel au sculpteur Pierre Sabatier ${ }^{28}$. Ce dernier envoie son devis le 26 novembre 1979 après une validation du projet par la commission départementale le 6 du même mois. L'accord définitif pour la pose des nouvelles portes est donné le 4 décembre 1979. Introduite par un perron à six degrés, chaque porte se compose de deux vantaux cernés par des parties pleines fixes qui présentent un aspect similaire. L'ensemble est inscrit en retrait dans un épais chambranle en béton recouvert de plaques métalliques. Les vantaux sont composés d'une armature métallique, elle-même revêtue d'un habillage en laiton recouvert d'étain oxydé dans les tons bronze et travaillé en relief: P. Sabatier a réalisé une trame régulière de petits éléments circulaires en forme de cabochons aplatis. Le format des deux portes leur permet de s'intégrer parfaitement dans le dessin de façade de R.-M. Barade, tout en conservant une certaine retenue par leurs dimensions modestes. 
Figure 17

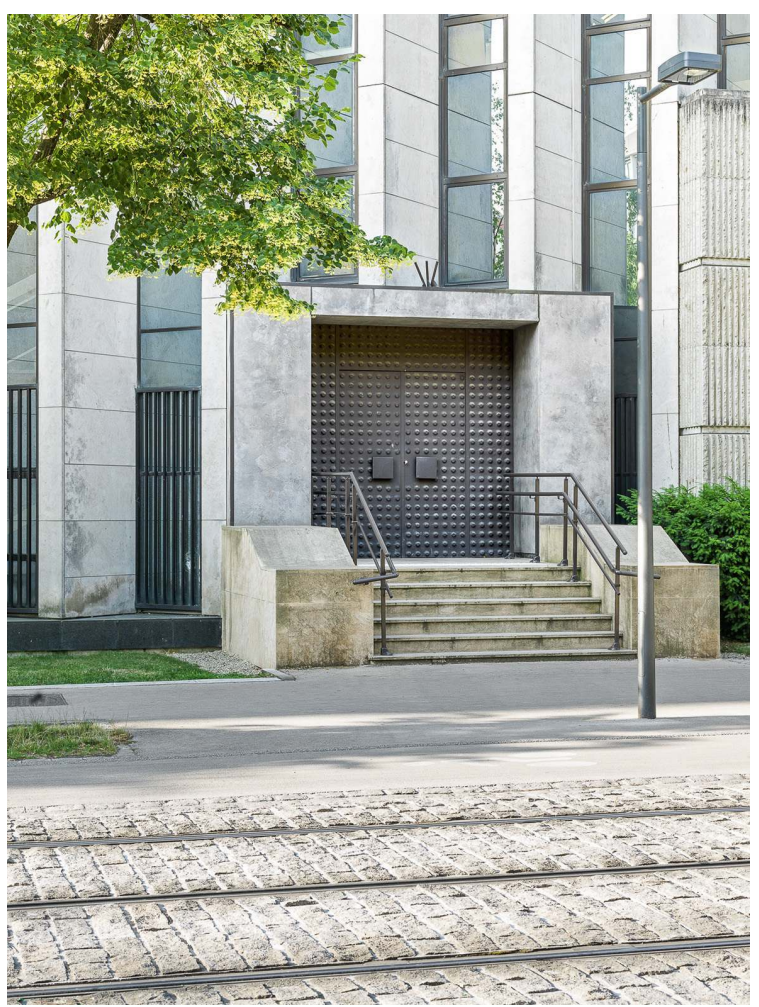

Hôtel de région : façade antérieure, porte nord.

Phot. Pierre-Marie Barbe-Richaud. (c) Service Patrimoine et inventaire, Région Bourgogne, 2014.

Le plan de masse respectant l'alignement du boulevard de la Trémouille est une des solutions utilisées par les architectes pour insérer leur création dans l'espace urbain. Le choix des matériaux reflète également ce parti. Si R.-M. Barade, en réponse à une question lors de la présentation de la première version du projet, avait expliqué qu'une façade en pierre n'était pas possible pour des raisons de structure et de coût, il offre ici une solution intermédiaire avec la série de lames de béton verticales recouvertes d'un parement de pierre du Châtillonnais et un parement imitant la pierre de taille travaillé pour le «marquage » de la salle des Assemblées au rez-de-chaussée. En associant un matériau traditionnel, la pierre, au béton et au verre, les architectes ont tenté un compromis entre un classicisme représentatif du travail de R.-M. Barade dans les années 1960 et une contemporanéité qui apparaîtrait trop marquée. Les baies vitrées participent également de la composition de l'ensemble pour accroître la solennité de l'immeuble. Réfléchissantes mais pas totalement opaques, elles renvoient en partie l'architecture environnante quand le spectateur se place à une certaine distance et permettent d'entrevoir l'intérieur lorsqu'il s'en rapproche. Cet effet s'observe particulièrement aux extrémités où sont situés les escaliers : sous un certain angle, le regard pénètre jusqu'aux vitres de la façade arrière.

Le parking souterrain occupe cinq niveaux, dont les deux premiers sont réservés aux véhicules $d u$ conseil général et $d u$ conseil régional. Un soubassement, abritant des sanitaires ainsi que des locaux techniques et d'archives, permet de surélever le rez-dechaussée où la salle des Assemblées s'organise autour de deux halls et de la galerie (fig. 18). 
Figure 18

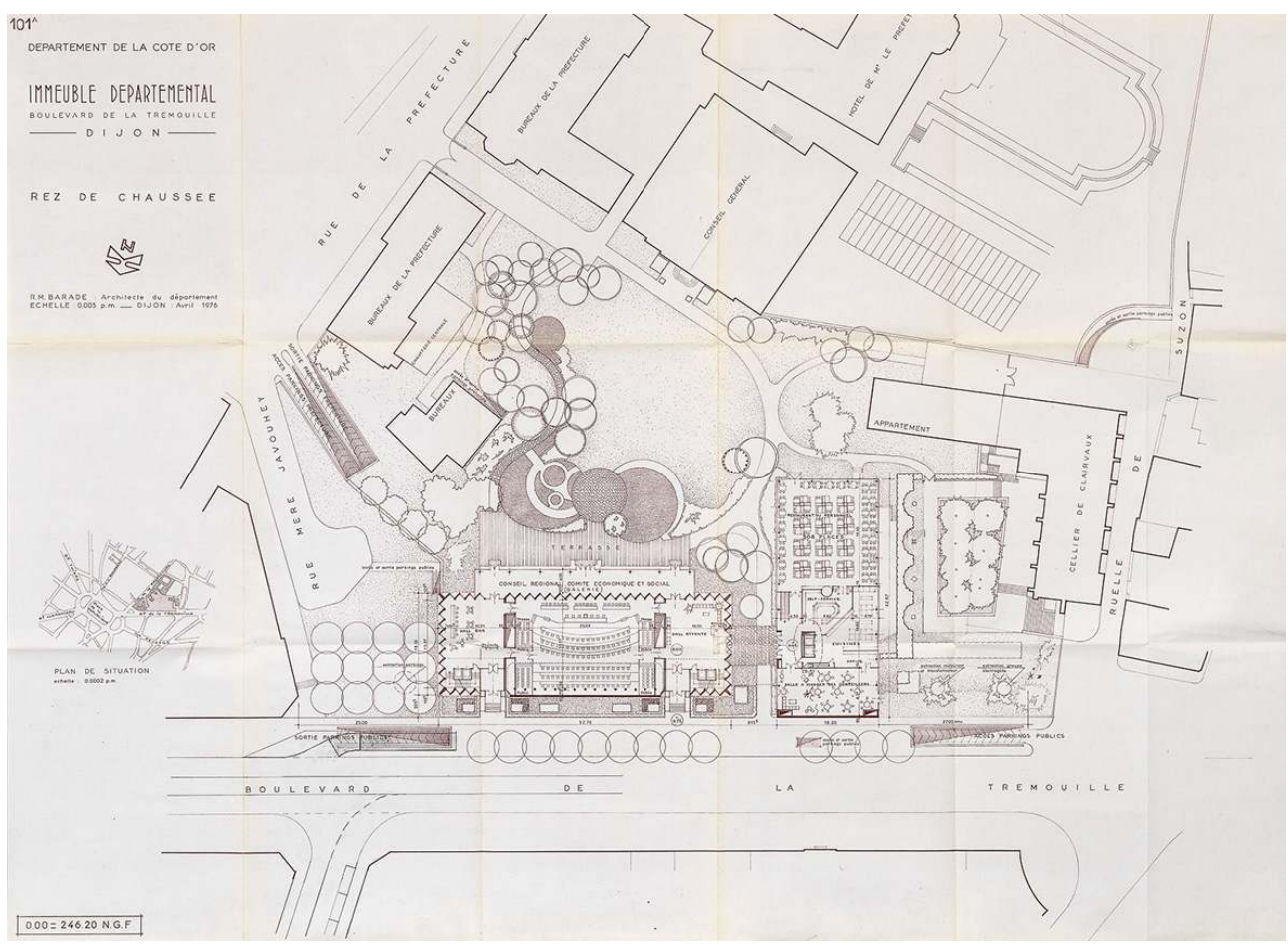

Roger-Martin Barade : second projet, plan de situation et du rez-de-chaussée, avril 1976.

Repro. Pierre-Marie Barbe-Richaud. Archives départementales de la Côte d'Or, 32 J 84 . (c) Service Patrimoine et inventaire, Région Bourgogne, 2014

Les voies de circulation verticales (ascenseurs et escaliers) sont placées à chaque extrémité de l'édifice. Le premier étage est à l'origine réservé aux bureaux des présidents et du préfet ${ }^{29}$. Viennent ensuite les deux derniers étages pour les bureaux des agents, ces derniers étant répartis de part et d'autre d'un couloir central (fig. 19). Le bâtiment se devait d'être avant tout un immeuble fonctionnel, abritant des bureaux pour les agents. Bien que les architectes aient tenu à réaliser des pièces de représentation et d'apparat au rez-de-chaussée, où prime une mise en scène luxueuse de l'espace, l'exigence principale pour les niveaux suivants reste la fonctionnalité ${ }^{30}$. 


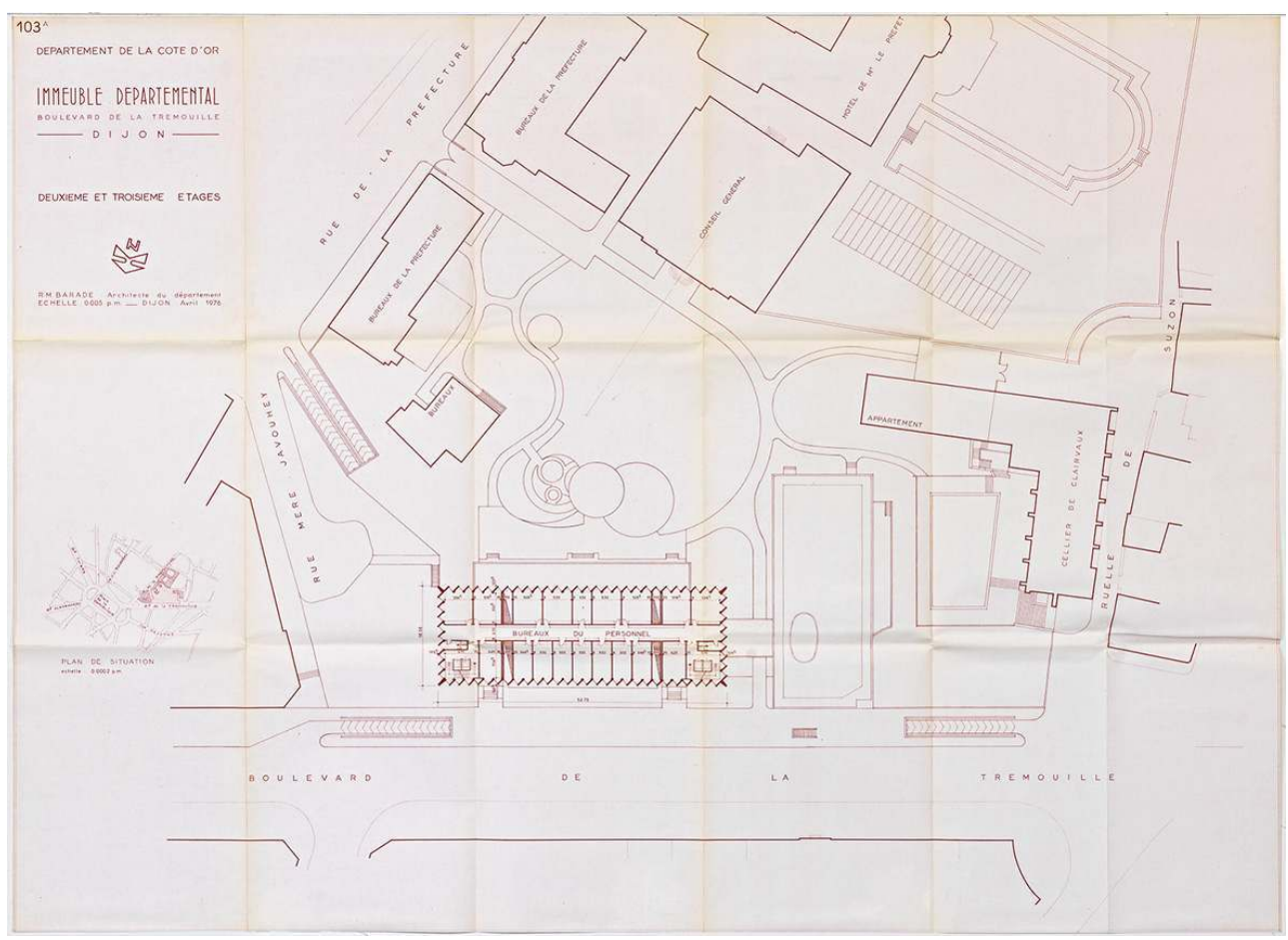

Roger-Martin Barade : second projet, plan des $2^{\mathrm{e}}$ et $3^{\mathrm{e}}$ étages, avril 1976.

Repro. Pierre-Marie Barbe-Richaud. Archives départementales de la Côte d'Or, 32 J 84. ( ) P.-M. BarbeRichaud, Service Patrimoine et inventaire, Région Bourgogne, 2014.

Dans la composition d'ensemble de l'hôtel de région, R.-M. Barade montre à nouveau sa maîtrise de l'organisation des vastes volumes, héritée de ses réalisations des années 1950 et 1960. Cette volonté d'insérer le nouvel immeuble dans la trame urbaine préexistante a cependant imposé une différenciation par rapport à une forme plus classique des architectures de l'Administration : l'absence de parvis. En effet, si l'édifice se démarque grâce aux voiries latérales qui introduisent une rupture dans la continuité du bâti, il n'en demeure pas moins qu'il ne dispose pas d'un espace de recul important. La construction du tramway a aujourd'hui permis de dégager en partie l'édifice de la voirie automobile, mais force est de constater qu'il ne dispose pas d'espace public comparable à celui de la place-parvis ${ }^{31}$ qui servirait à la fois de lieu d'introduction, de mise en valeur du bâtiment mais aussi de (re)présentation pour la collectivité.

Cette approche d'insertion urbaine se retrouve dans les chantiers des hôtels des régions Centre et Limousin (architecte : Christian Langlois) où la volonté d'harmonisation par le biais d'une architecture contemporaine au visage néo-classique a imposé une continuité de la trame urbaine et donc, à nouveau, l'absence de place-parvis. Si l'espace urbain est assez dégagé devant l'hôtel de région Centre, c'est que le bâtiment s'inscrit dans un projet plus global, celui des abords de la cathédrale. Le parvis est donc davantage conçu pour mettre en valeur la cathédrale que pour l'immeuble régional lui-même en tant que tel. Quant à l'hôtel de région Limousin, c'est un édifice bâtiment formé de plusieurs corps de logis qui enserre son îlot d'implantation sur trois côtés. La façade antérieure présente une petite cour entourée de grilles et les angles nord et sud de légers retraits. Mais aucun de ces espaces ne peut prétendre à la fonction de place-parvis avec un rôle d'introduction et de mise en valeur de l'édifice dans son environnement urbain. 

dégagement mais dont la proximité immédiate avec un boulevard urbain entraîne la même absence de place au-devant du bâtiment. Il est donc possible de s'interroger sur ces nouvelles formes urbaines et architecturales que sont les hôtels de région à partir des années 1975/1980. L'absence de place-parvis serait-elle une caractéristique des nouvelles architectures officielles des pouvoirs publics ou bien la raison est-elle davantage liée aux contraintes patrimoniales et urbaines avec la nouvelle vision de la ville qui émerge dans ces mêmes années ? Il paraît délicat d'établir des généralités à ce sujet tant l'opération du quartier Antigone à Montpellier, achevée avec l'édification de l'hôtel de région Languedoc-Roussillon en 1988, en est un contre-exemple de poids. Le bâtiment est effectivement le point final de ce programme immobilier et l'ensemble des aménagements urbains participe à sa mise en valeur avec un véritable parvis. En revanche, il convient de préciser que ce dernier cas est le fruit d'un projet ex-novo d'une ampleur urbaine considérable, ce qui en fait une exception. En effet, les contraintes urbaines ne sont absolument pas comparables à celles d'un immeuble neuf édifié dans un site urbain dense et ancien.

Pour le cas de l'hôtel de région Bourgogne, la réponse est peut-être à chercher dans les premiers projets de 1974. Ces derniers supposaient bien la création d'un nouvel espace public avec la nouvelle rue perpendiculaire au boulevard de la Trémouille. Avec le perron couvert par un auvent, l'ensemble pouvait revêtir les fonctions d'une place-parvis (voir fig. 6). Or, dans la dernière version du projet de 1976, cet espace de circulation entre les différents bâtiments de la préfecture, du conseil général et du conseil régional est placé à l'arrière du futur immeuble : il s'agit du jardin (voir fig. 18). Cet espace vert peut être perçu comme une version modifiée du parvis traditionnel, désormais relégué à l'arrière et dont la fonction principale est devenue celle d'un espace de desserte et de circulation.

31 En outre, R.-M. Barade a réfléchi à la composition du jardin afin qu'il s'harmonise au mieux avec le dessin de la façade. Dans les premières esquisses, c'est un jardin à la française qui est imaginé. Mais dans les dernières versions, l'architecte s'oriente plutôt vers un agencement où prédominent les courbes que ce soit pour les parterres végétalisés, les bassins d'eau ou les chemins piétons. Il faut donc bien percevoir le jardin comme faisant partie intégrante du projet des architectes. Son dessin, aux accents circulaires marqués, ayant effectivement été conçu comme un complément au bâtiment, où triomphent les lignes droites (fig. 20). 


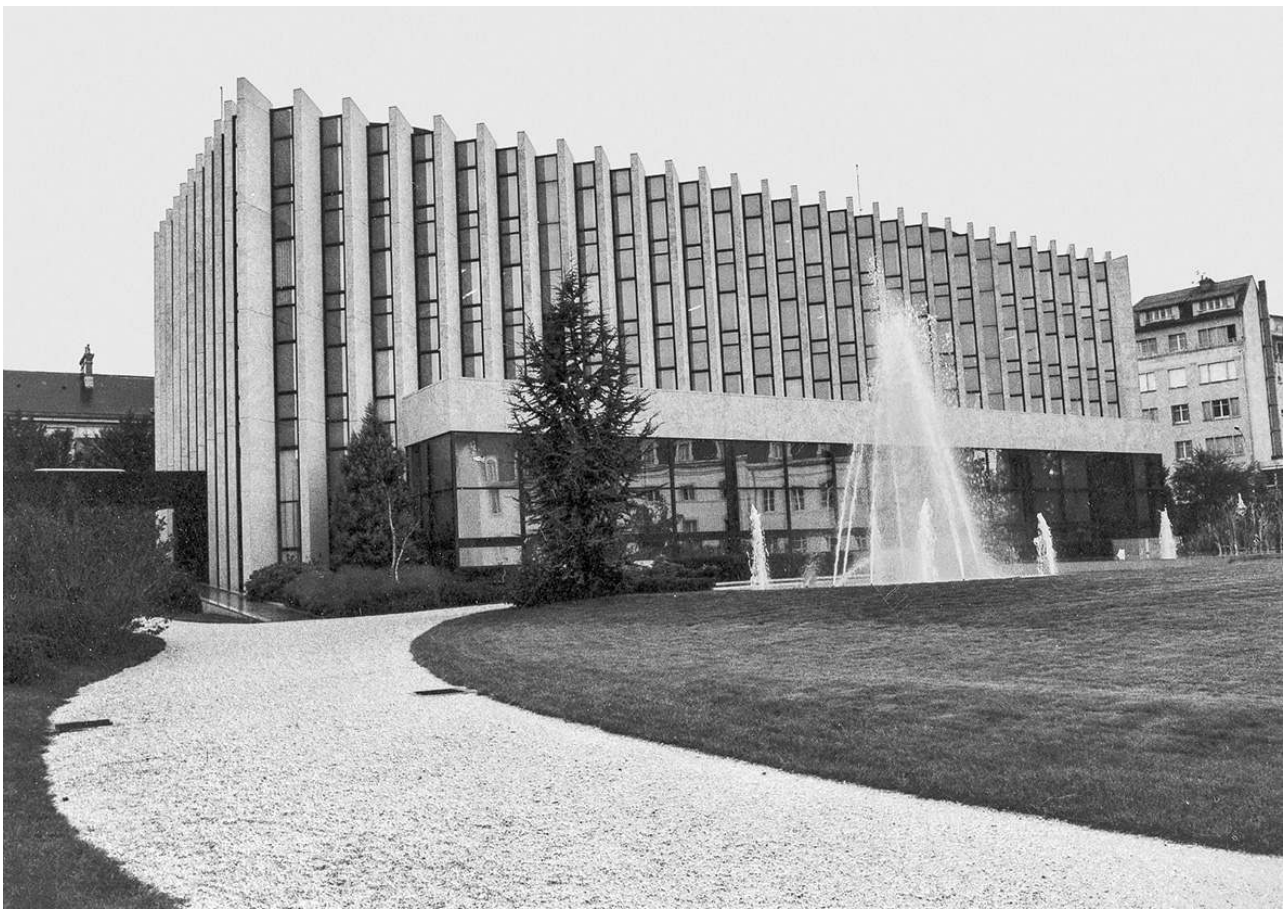

Hôtel de région : façade postérieure, photographie ancienne, ca. 1995-2000.

Repro. Pierre-Marie Barbe-Richaud. Direction de la communication, Région Bourgogne. (C) Service Patrimoine et inventaire, Région Bourgogne, 2014

\section{Le recours aux artistes : une décoration représentative du goût des années 1970}

Dans les premières notices explicatives des projets, tant le premier (avril 1975) que le second (septembre 1975), la partie réservée à la décoration et à l'ameublement intérieurs n'est que peu développée. R.-M. Barade ne fait mention que d'une éventuelle pièce de tapisserie murale pour la grande salle de réunion ou de panneaux décoratifs dans le hall. Néanmoins, au fur et à mesure que progresse la réflexion des architectes sur le projet général du futur édifice, l'attention portée aux éléments de décor intérieur évolue. Ainsi, dans la notice descriptive du 9 avril 1976, si les mentions consacrées à la décoration restent laconiques, une paroi coulissante dans une salle qui servirait alors "pour les séances du Conseil Régional ou du Comité Économique et Social ainsi que pour les réunions plénières » est prévue. Dans le devis descriptif datant du 16 du même mois, des précisions sont apportées pour la salle des Assemblées mais elles demeurent succinctes. R.-M. Barade y imagine "un revêtement en menuiserie bois apparent participant au traitement acoustique $\aleph^{32}$ auquel s'adjoint une cloison repliable au centre de la salle, également en "menuiserie bois apparent $\aleph^{33}$. À l'inverse, pour le hall, il est prévu un « revêtement en acier inox " $^{34}$.

Les architectes décident alors de faire appel à plusieurs artistes de renom : Pierre Sabatier pour la salle des Assemblées, Denis Morog pour les panneaux sculptés du hall et Michel Boyer pour l'ameublement et l'aménagement intérieur. Le conseil donné par Henry Bernard - dans ce langage sans doute propre au milieu des architectes - «faire de 
l'architecture $\aleph^{35}$, semble avoir été suivi par les auteurs du futur hôtel de région tant pour l'aspect extérieur que pour l'intérieur de l'édifice. Ils ont effectivement apporté un soin particulier à l'élaboration des façades, mettant en scène un vocabulaire architectural moderne et imposant. Cette aspiration à une «monstration» grandiloquente s'est poursuivie, voire amplifiée, à l'intérieur, avec la volonté d'installer une véritable scénographie décorative, représentative du goût en matière de décor de la seconde moitié des années 1970.

\section{Pierre Sabatier : le décor de la salle des Assemblées}

Pierre Sabatier (1925-2003) est l'auteur de deux œuvres au sein de l'hôtel de Région : les panneaux métalliques de la salle des Assemblées et les deux principales portes d'entrée.

Salle des Assemblées, salle du conseil, salle plénière du conseil, salle des délibérations, hémicycle, etc., les termes sont nombreux pour désigner l'espace de réunion des élus d'un conseil régional. Cette pièce représente le cœur de l'institution, le lieu où sont votés les projets et actions menés par la collectivité. C'est pour répondre à la valeur symbolique et significative de la salle des Assemblées que R.-M. Barade, suivant les conseils d'Henry Bernard, a choisi de signaler son emplacement sur la façade principale. Le traitement intérieur de la salle du Conseil revêtait également une importance particulière. Dans un espace rectangulaire, les fauteuils des conseillers sont disposés en hémicycle, face à la tribune présidentielle. Après l'allée centrale, les rangées redeviennent droites. Des loges pour la presse et les visiteurs sont installées aux extrémités, à côté des portes d'accès (fig. 21).

Figure 21

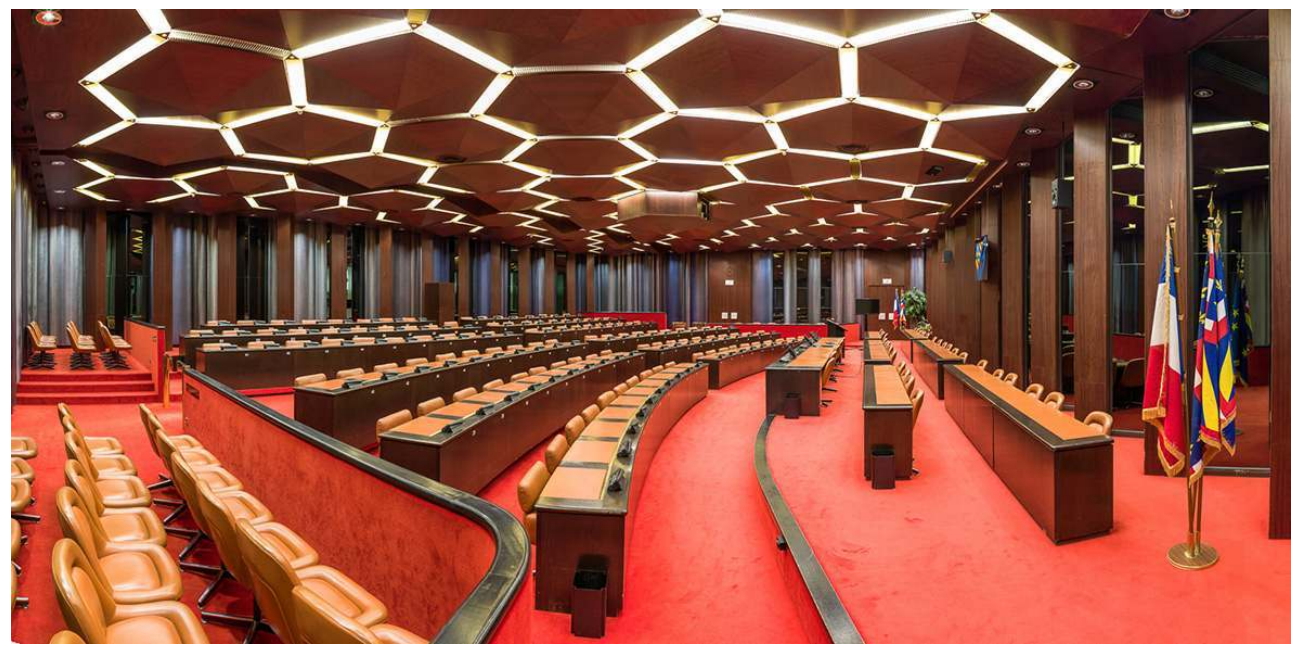

Hôtel de région : salle des Assemblées.

Phot. Pierre-Marie Barbe-Richaud. (C) Service Patrimoine et inventaire, Région Bourgogne, 2014

Comme dit précédemment, les panneaux métalliques semblaient au départ être prévus pour le hall, à l'instar de la création du sculpteur pour la tour Manhattan, dans le quartier de La Défense, en 1975 (arch. Michel Herbet et Michel Proux). L'architecte dijonnais avait découvert P. Sabatier avec son panneau mural de la nouvelle préfecture de Créteil (1971) ${ }^{36}$ . Les deux artistes ont ensuite travaillé ensemble pour le nouveau bâtiment des sciences du campus universitaire de Dijon $^{37}$, le sculpteur réalisant une installation murale 
lumineuse pour le hall d'entrée. La mention d'un « revêtement en acier inox dans le hall d'entrée $\aleph^{38}$ dans le devis descriptif indique que R.-M. Barade et P. Sabatier étaient sûrement déjà en contact en avril 1976 pour la décoration du futur bâtiment. La consultation du fonds Barade ainsi que celui de Pierre Sabatier ${ }^{39}$ permet d'affirmer que c'est bien à partir de 1976 que les deux hommes de l'art échangent régulièrement pour mettre au point le décor intérieur. En revanche, si les lettres de l'architecte au sculpteur nous renseignent sur le fait qu'à partir du mois de novembre 1976, R.-M. Barade a finalement choisi d'installer le revêtement mural en aluminium dans la salle des Assemblées ${ }^{40}$, rien ne nous permet de savoir ce qui a induit ce changement en cours d'année.

Le revêtement mural de P. Sabatier est composé d'une série de panneaux ondulés en aluminium, disposés sur trois des quatre murs de la salle des Assemblées (fig. 22). Une série de miroirs, dont l'artiste a choisi la teinte, est installée en alternance sur certaines parois pour des questions techniques : il s'agit en réalité de vitres sans tain séparant la grande salle des pièces plus petites annexes (régie, espace de stockage, etc.).

Figure 22

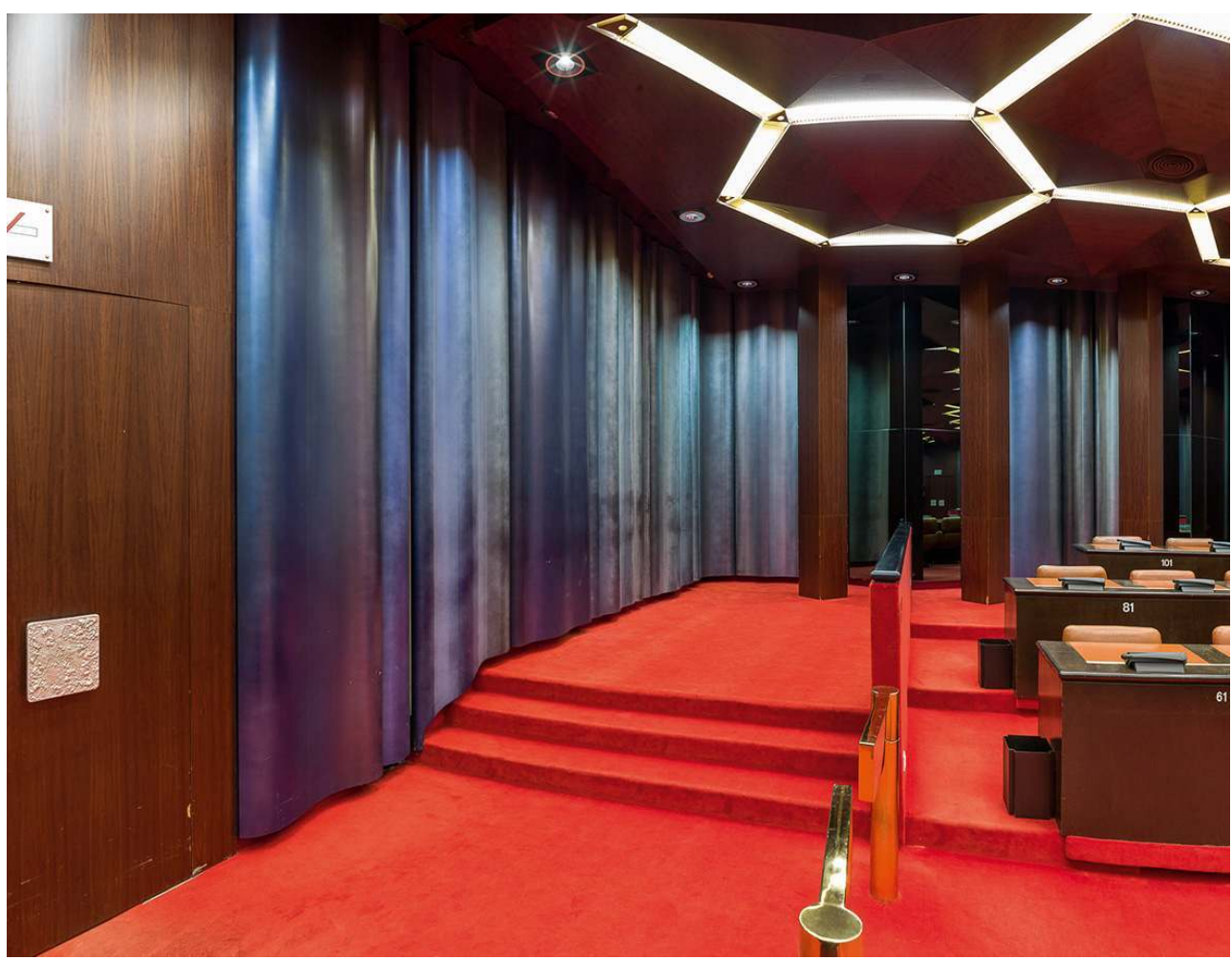

Hôtel de région : salle des Assemblées, panneaux métalliques de Pierre Sabatier sur le mur sud. Phot. Pierre-Marie Barbe-Richaud. (c) Service Patrimoine et inventaire, Région Bourgogne, 2014.

La composition des panneaux est identique à celle que P. Sabatier a utilisée pour la tour de La Défense : en aluminium ${ }^{41}$, avec un effet nacré obtenu grâce à l'« incorporation dans des résines cellulosiques de paillettes de mica, produisant par interférences optiques des brillances colorées... $»^{42}$, à laquelle s'ajoute l'utilisation de cristaux de plomb qui produisent des effets colorés variables selon l'éclairage (fig. 23). L'effet cinétique, obtenu par réflexion de la lumière directe ou réfléchie, est accentué par le traitement différent des creux des côtés et des sommets des ondes ${ }^{43}$. 
Figure 23

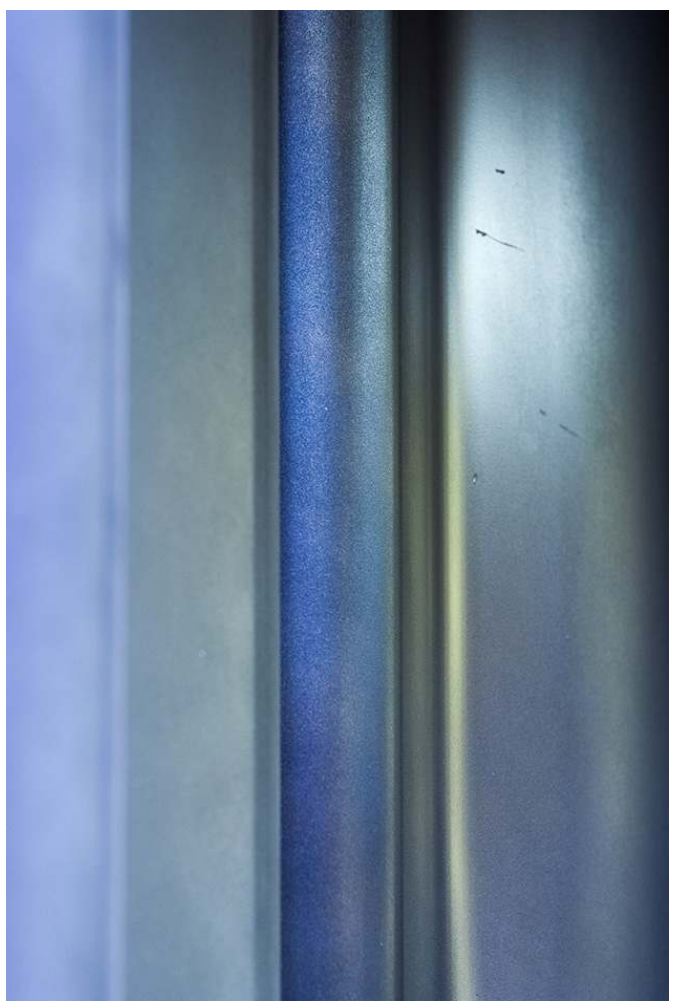

Hôtel de région : salle des Assemblées, détail des panneaux métalliques de Pierre Sabatier.

Phot. Pierre-Marie Barbe-Richaud. (c) Service Patrimoine et inventaire, Région Bourgogne, 2014

R.-M. Barade choisit également d'employer des panneaux réalisés par P. Sabatier pour la cloison amovible permettant de séparer la salle en deux espaces (fig. 24, fig. 25). Cette cloison coulissante était déjà prévue dans le devis d'avril 1976. Stockés dans les espaces de rangement disposés autour de la salle principale, ces panneaux, collés sur des planches de contreplaqué, sont fixés sur un rail installé entre les panneaux de bois du plafond. Lorsqu'ils sont déployés, l'impression d'un voile métallique suspendu est accentuée et il est alors possible de saisir toute la qualité plastique de cette création : les variations des ondulations s'harmonisent avec les reflets nacrés, soulignés par l'éclairage rasant. 
Figure 24

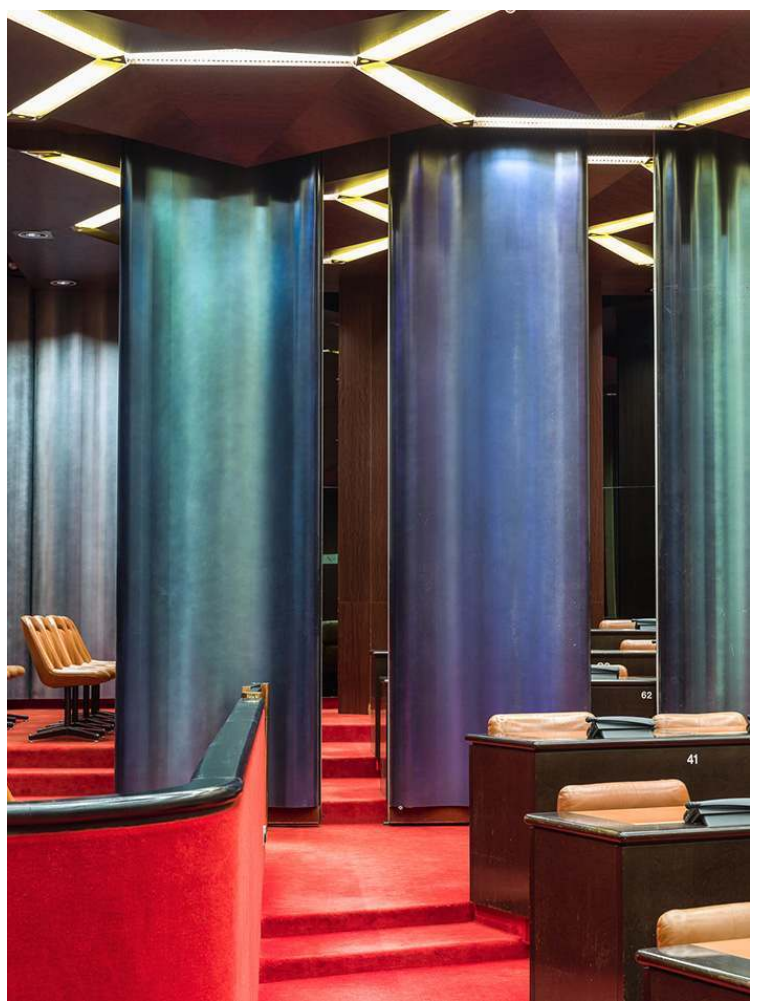

Hôtel de région : salle des Assemblées, panneaux métalliques de Pierre Sabatier pour la cloison amovible.

Phot. Pierre-Marie Barbe-Richaud. (C) Service Patrimoine et inventaire, Région Bourgogne, 2014. 
Figure 25

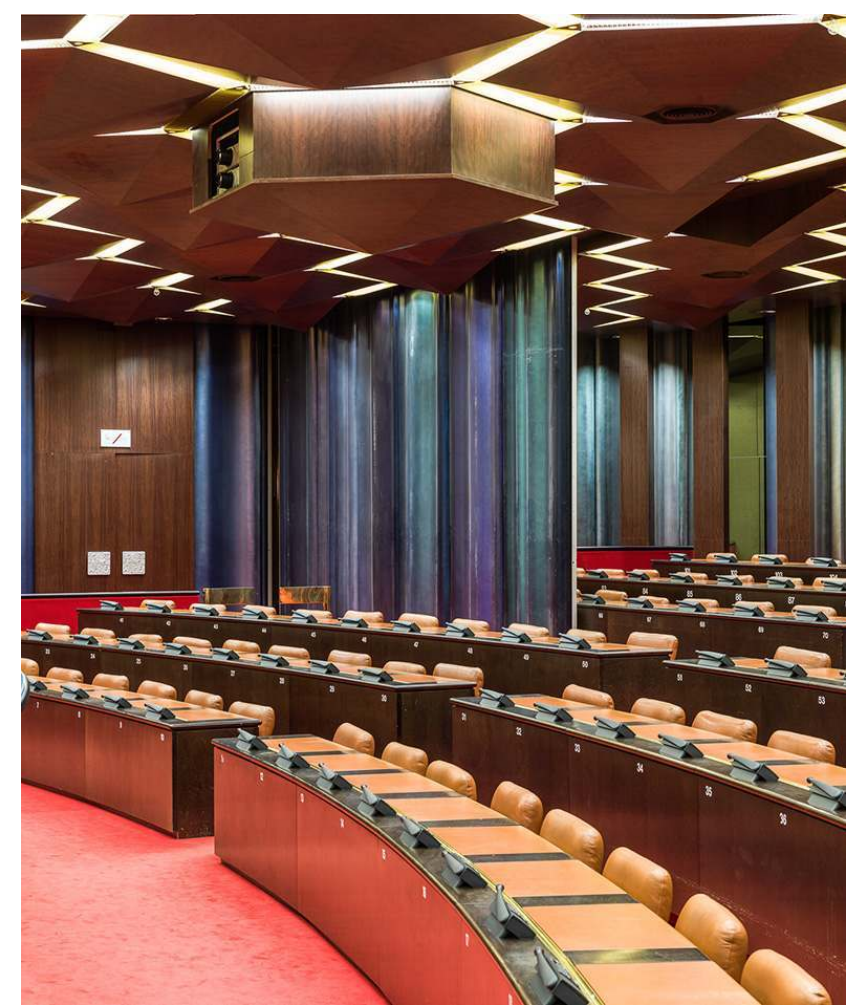

Hôtel de région : salle des Assemblées, panneaux métalliques de Pierre Sabatier pour la cloison amovible.

Phot. Pierre-Marie Barbe-Richaud. (C) Service Patrimoine et inventaire, Région Bourgogne, 2014.

Quant aux coloris, P. Sabatier a souhaité utiliser un panel de nuances allant du bleu sombre au gris, avec pour certains panneaux des reflets violets, turquoise et vert d'eau. L'éclairage joue ici un rôle important puisque, en fonction de l'orientation des projecteurs, les teintes des reflets varient. À noter que les panneaux fixés aux murs de la salle paraissent avoir perdu en saturation, tandis que ceux fixés sur les rails (moins utilisés et donc souvent remisés dans les espaces de stockage) conservent des coloris plus soutenus.

41 La création de P. Sabatier pour la salle des Assemblées est représentative de son travail au cours de la décennie 1970. En effet, s'il avait déjà travaillé le métal dans les années 1960, il semble avoir orienté véritablement sa production vers ce médium. La première œuvre où il fait usage des panneaux ondulés en aluminium est le hall de la tour Manhattan en 1975. Cette installation, par le succès qu'elle a rencontré ${ }^{44}$, a offert une visibilité plus grande à son travail. On ne sait si c'est R.-M. Barade qui a proposé à P. Sabatier de reprendre le même principe pour la salle des Assemblées ou l'inverse, en revanche il est certain que l'architecte a été à son tour séduit par l'impression d'unité offrant en même temps une animation murale inédite.

Le travail de P. Sabatier pour la tour de La Défense devait faire écho à la forme extérieure du bâtiment et être en "osmose avec l'architecture de la tour » avec un sentiment de continuité mais en utilisant des matériaux différents (travail sur les reflets, les galbes, le côté glacé). En revanche, pour l'hôtel de région, l'objectif semble plus d'adoucir l'espace rectangulaire de la pièce par le jeu des courbes. L'approche et la mise en œuvre technique 
sont certes similaires, mais les archives conservées dans l'atelier de l'artiste révèlent le soin qu'il a apporté à l'ordonnancement des panneaux en fonction des nuances de couleur. Une partie de son travail consista également à rechercher l'ondulation idéale qu'il souhaitait conférer à ses panneaux. Il réalisa ainsi plusieurs esquisses avec une projection en plan afin d'étudier la meilleure manière de raccrocher les panneaux placés au niveau de l'angle d'un mur. P. Sabatier et R.-M. Barade ont travaillé en étroite collaboration, ce dernier invitant même le sculpteur à choisir la teinte des glaces devant être placées entre certains panneaux en aluminium ${ }^{45}$.

Excepté les panneaux de P. Sabatier, c'est une harmonie de coloris chauds qui domine avec les différents médiums déployés dans la salle des Assemblées: cuir havane des fauteuils, bois pour le plafond et les bureaux, moquette rouge.

Le parti de R.-M. Barade d'installer un décor composé de panneaux en aluminium dans cette vaste salle peut s'expliquer par la prééminence du bois des autres panneaux muraux, les caissons en acajou du plafond ainsi que les bureaux des élus. Le sentiment de confinement induit par ce matériau, présent du sol au plafond, est ainsi atténué par le contraste des couleurs et des matières. Les panneaux métalliques aux couleurs froides auraient pu causer une rupture bichromique trop franche, mais elle est tempérée grâce aux ondulations et aux effets nacrés. La différence de coloris permet justement de ne pas rendre l'espace trop étouffant et d'offrir une certaine respiration aux murs. L'ensemble du traitement décoratif confère ainsi à la salle des Assemblées une véritable apparence de lieu de représentation.

\section{Denis Morog : le béton architectonique ou l'art englobant l'espace}

Curieusement, très peu de documents d'archives ont été conservés dans le fonds Barade des Archives départementales de la Côte-d'Or sur les créations de Denis Morog ${ }^{46}$ pour le hall de l'hôtel de région. Cette absence est d'autant plus étonnante que le travail du sculpteur s'avère être une œuvre de grande ampleur (fig. 26, fig. 27). 


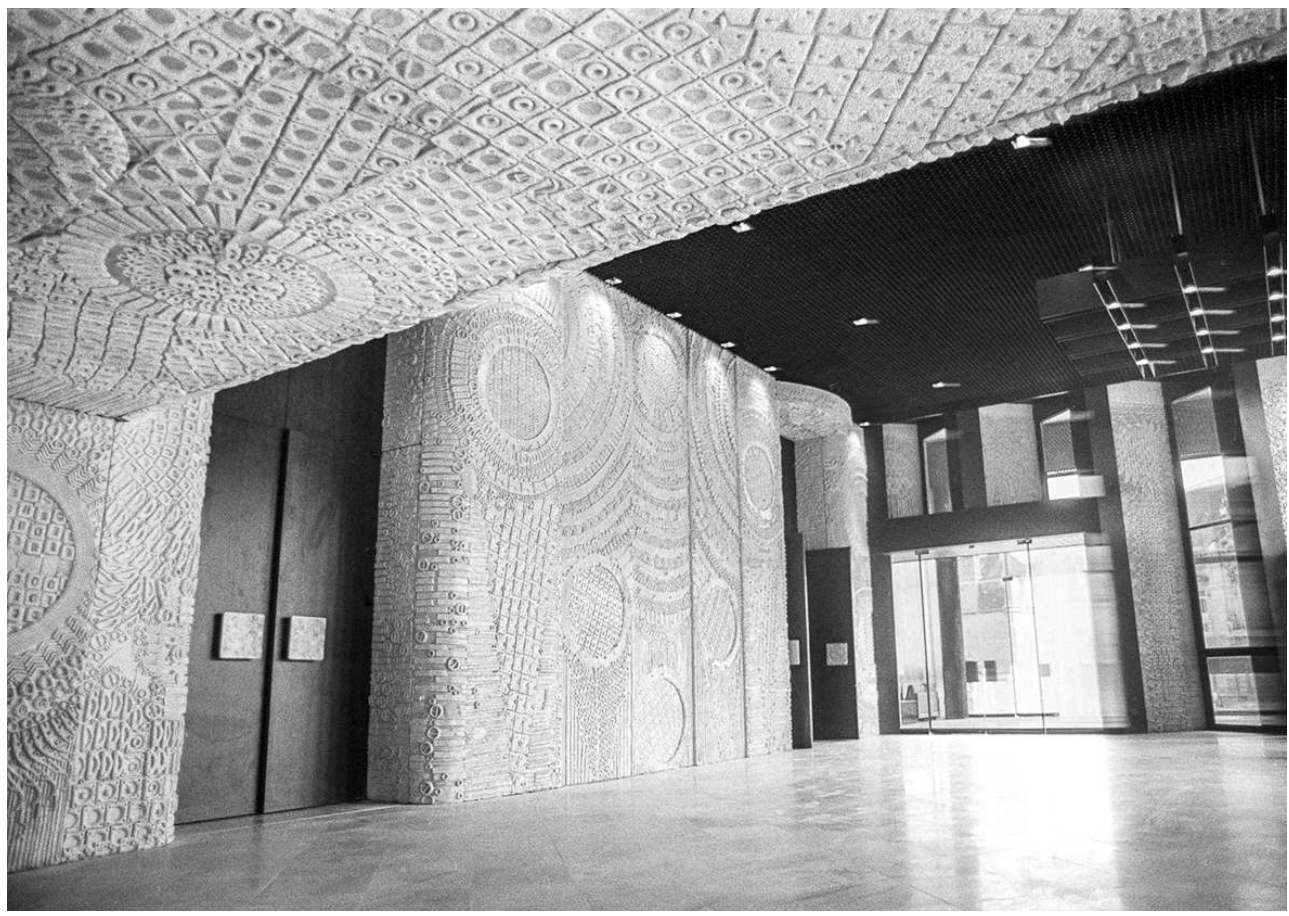

Hôtel de région : hall d'accueil, photographie ancienne, ca. juin 1980.

Repro. Pierre-Marie Barbe-Richaud. (c) Archives Le Bien Public.

Figure 27

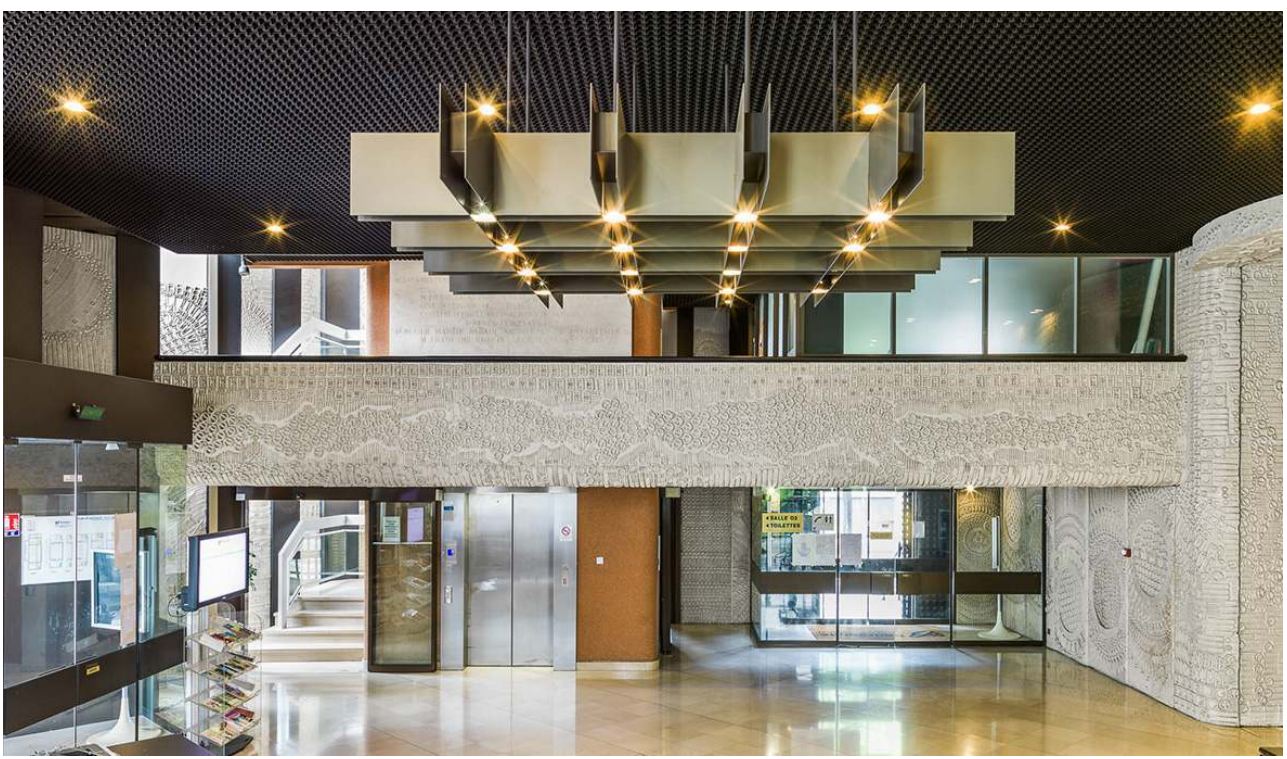

Hôtel de région : hall d'accueil.

Phot. Pierre-Marie Barbe-Richaud. (c) Service Patrimoine et inventaire, Région Bourgogne, 2014

Dans le devis d'avril 1976, R.-M. Barade prévoit encore un revêtement en acier inox pour les murs du hall d'accueil. C'est certainement très peu de temps après qu'évolue le choix pour la décoration de cet espace, les documents d'archives révélant que l'architecte et le 
sculpteur sont en contact depuis la fin de l'année $1976^{47}$. Les créations de D. Morog sont ensuite installées par l'entreprise chargée des travaux de menuiserie entre 1979 et 1980.

Les quatre murs du hall d'accueil sont ainsi recouverts de panneaux en béton moulé, de dimensions variables selon la surface disponible (fig. 28) (voir fig. 32).

Figure 28

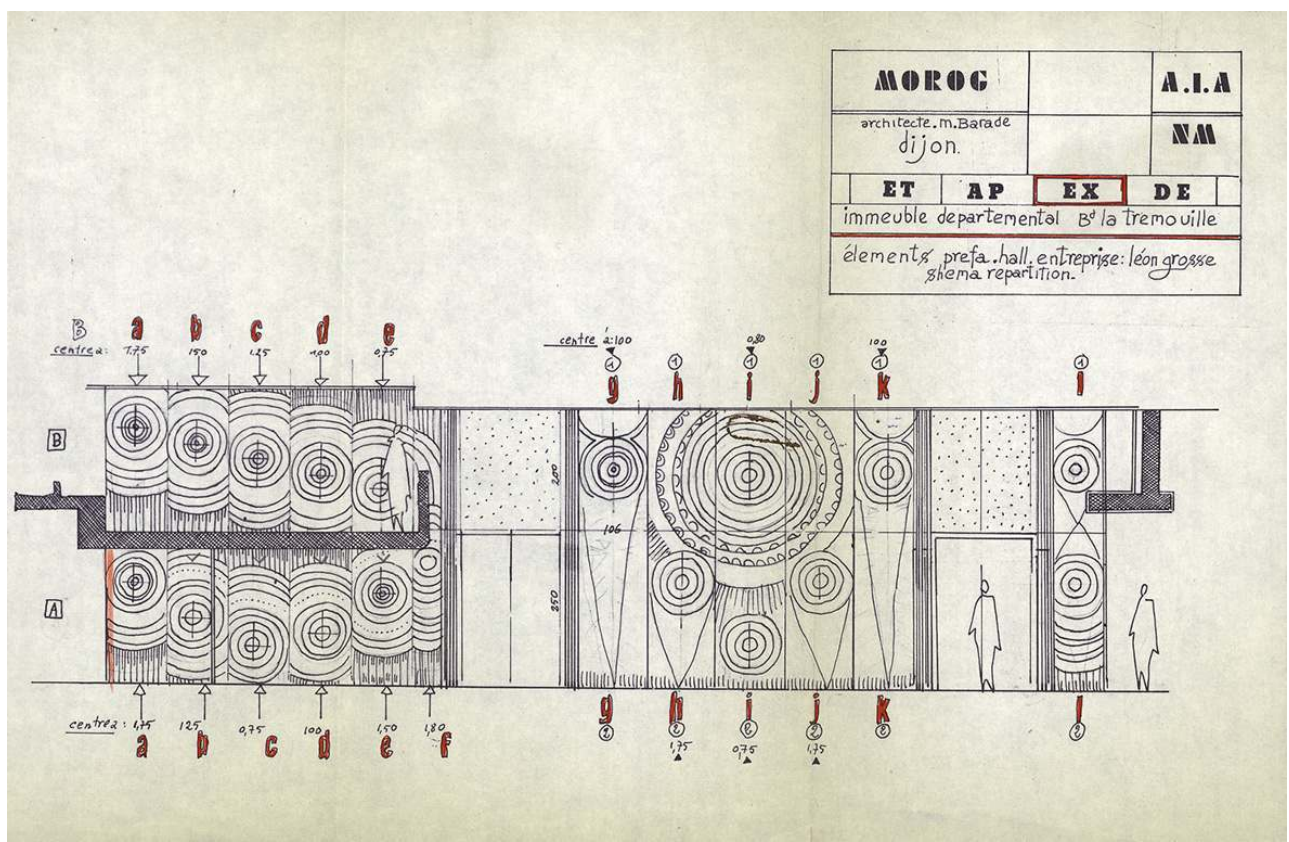

Denis Morog : schéma de répartition des éléments préfabriqués pour le hall, sd.

Repro. Frédéric Petot. Archives départementales de la Côte-d'Or, 32 J 82. (C) CG21/F.Petot/2014, Réutilisation soumise à conditions.

L'ensemble présente une dominante de formes courbes et circulaires avec notamment le motif du cercle que l'on retrouve sur la quasi-totalité des panneaux en tant que leitmotiv de cette œuvre. Sont également reproduits sur les panneaux différents motifs répétitifs (carrés, triangles, flèches, etc.), très certainement réalisés grâce à une matrice à l'aide de laquelle l'artiste creusait le polystyrène (fig. 29). On sait d'ailleurs que D. Morog forgeait souvent lui-même ses propres modules, variant les tailles et les formes en fonction des nécessités de la réalisation. Il chauffait ensuite ses fers au rouge afin de mieux pénétrer la matière des coffrages. 
Figure 29

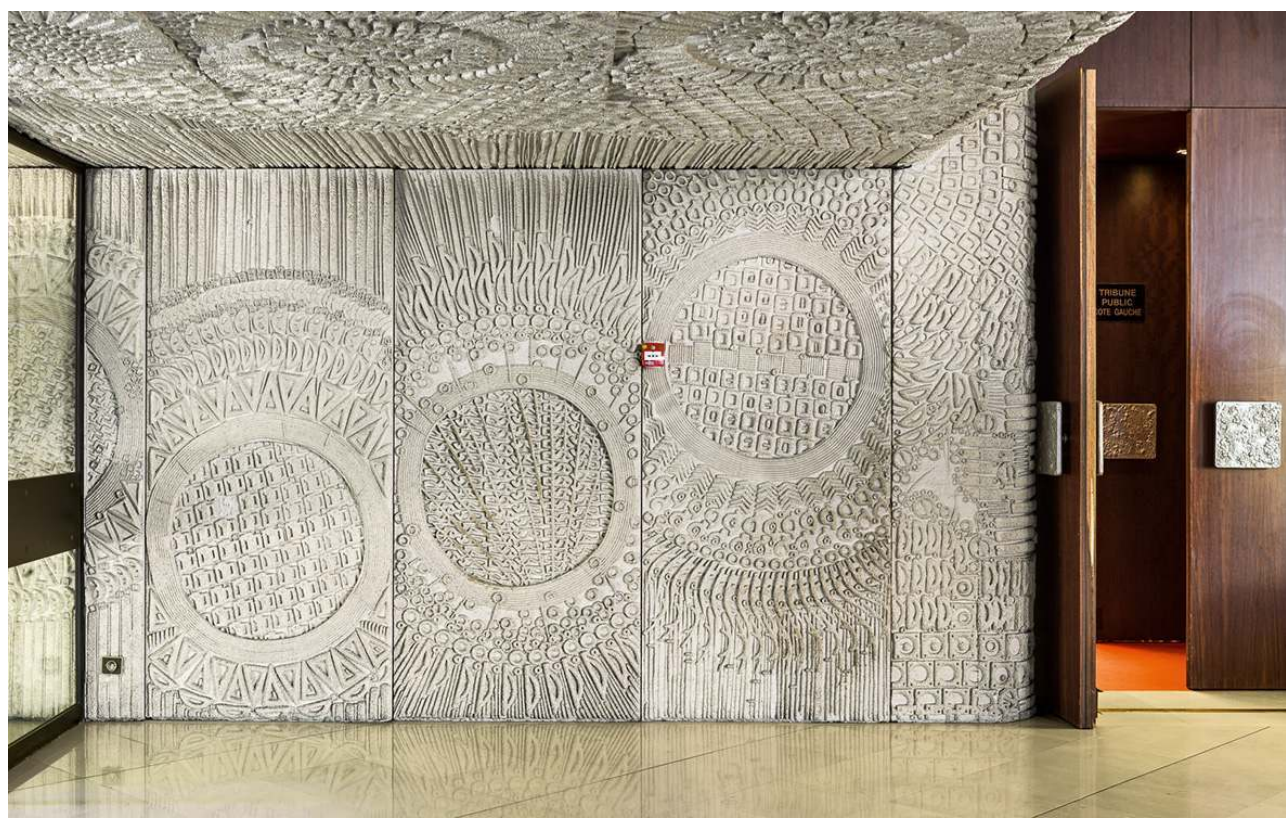

Hôtel de région : hall d'accueil : mur nord, panneaux en béton sculpté de Denis Morog.

Phot. Pierre-Marie Barbe-Richaud. (C) Service Patrimoine et inventaire, Région Bourgogne, 2014

Le décor prévu par D. Morog est également installé au niveau de la mezzanine (fig. 30). Pour les panneaux placés sur le mur de garde-corps, l'artiste adapte la taille des motifs afin d'en placer un nombre toujours important pour remplir au mieux l'espace. C'est d'ailleurs sur un de ces panneaux que semble se trouver sa signature: un petit $\mathrm{M}$ majuscule discrètement placé dans un angle et se mêlant aux autres bâtonnets (fig. 31). D. Morog signe régulièrement ses œuvres avec son nom complet inscrit dans un bouton en amande; mais il peut également adapter sa signature afin qu'elle s'harmonise avec le dessin général de l'œuvre, ce qui est le cas ici. On retrouve d'ailleurs une signature identique dans les panneaux réalisés pour l'entrée piétonne du parking de la gare de Dijon, rue des Perrières (1987). 
Figure 30

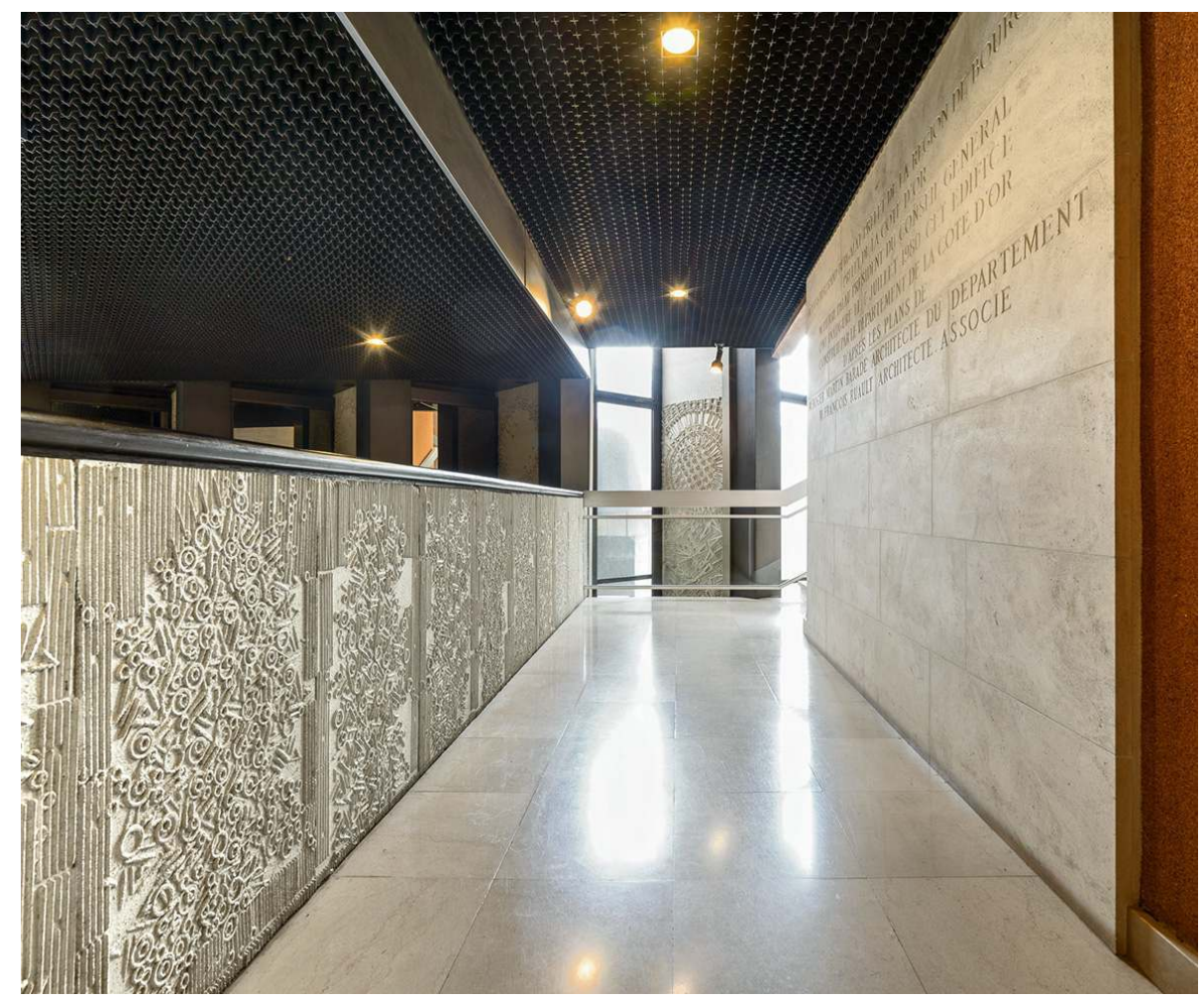

Hôtel de région : hall d'accueil : couloir de la mezzanine, panneaux en béton sculpté de Denis Morog. Phot. Pierre-Marie Barbe-Richaud. (c) Service Patrimoine et inventaire, Région Bourgogne, 2014. 


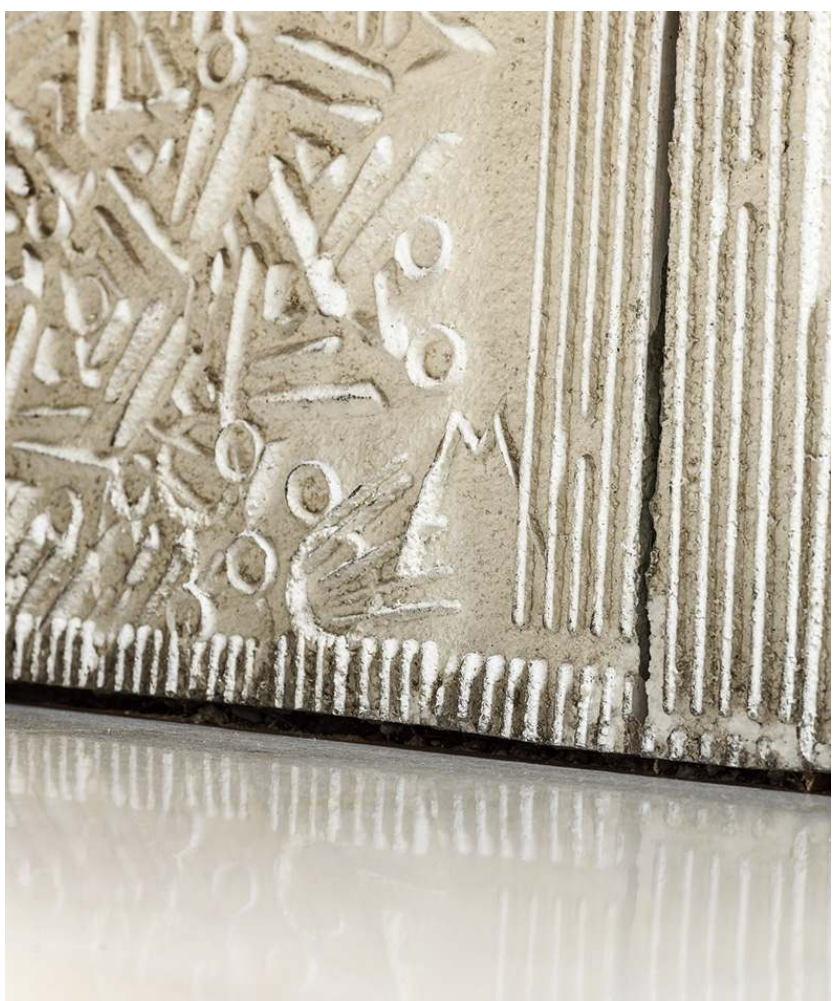

Hôtel de région : hall d'accueil : couloir de la mezzanine, panneaux en béton sculpté de Denis Morog, détail de la signature.

Phot. Pierre-Marie Barbe-Richaud. (c) Service Patrimoine et inventaire, Région Bourgogne, 2014.

Sans documents d'archives précis ${ }^{48}$, il n'est pas évident de décrire avec justesse la technique employée par D. Morog pour les panneaux du hall. Il réalise traditionnellement des moules ou coffres en polystyrène qui forment une gravure en négatif dans lesquels il coule ensuite le béton. Une fois les moules retirés, les panneaux sont installés, révélant ainsi les motifs qui couvrent les parois. C'est très certainement ce même procédé qui fut utilisé pour l'hôtel de région; il est en effet possible d'observer l'empreinte des billes du polystyrène expansé sur les panneaux.

51 Au final, les panneaux sont un mixte entre gravure et sculpture. De la première, D. Morog capte l'expérience pour animer une surface plane, de la seconde, il utilise la capacité à donner du volume au béton et de le mettre en scène dans l'espace (fig. 32). 
Figure 32

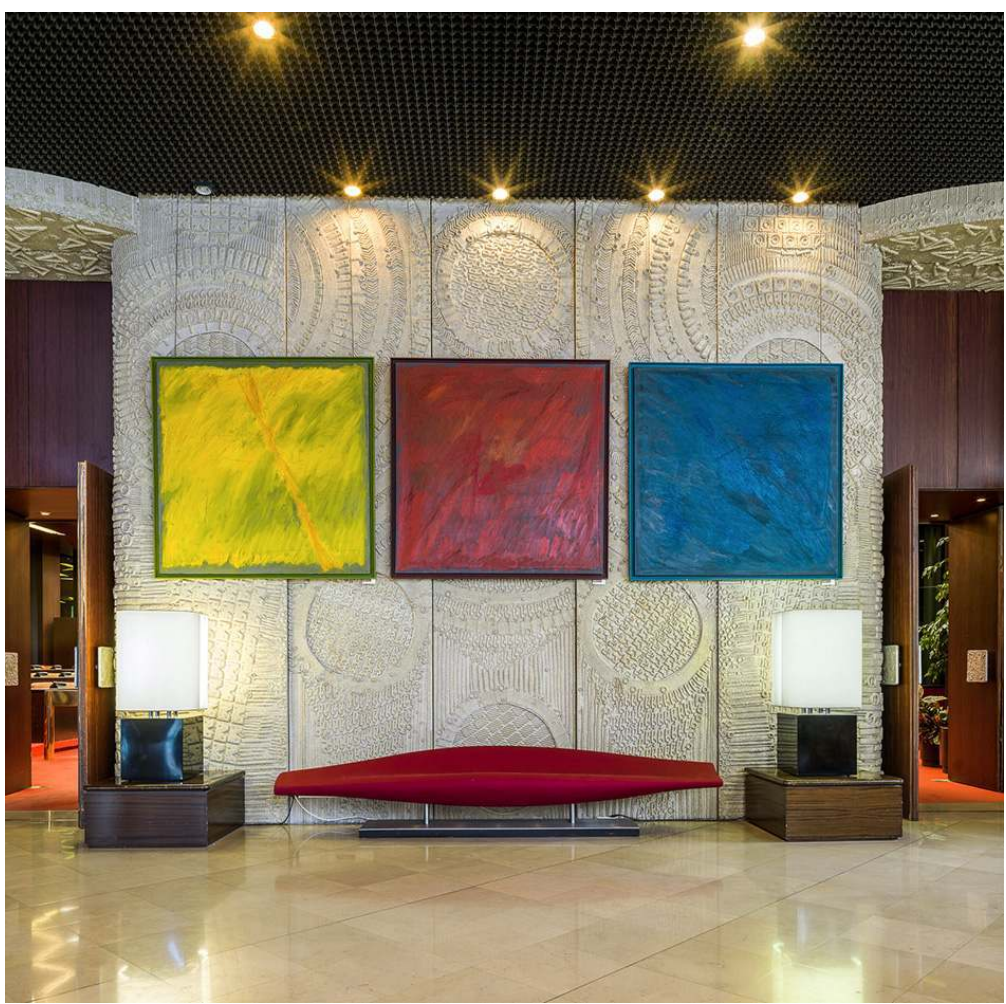

Hôtel de région : hall d'accueil : mur nord, panneaux en béton sculpté de Denis Morog.

Phot. Pierre-Marie Barbe-Richaud. (c) Service Patrimoine et inventaire, Région Bourgogne, 2014

Ce qui l'intéresse dans son médium de prédilection, c'est sa docilité : «Il sait prendre toutes les formes et participer aux réalisations les plus hardies. Des progrès considérables ont été réalisés quant à son aspect. Matériau d'innovations, il s'adapte à tous les problèmes ; on peut penser béton et couleurs, on peut penser béton léger, béton lourd, béton œuvre d'art, béton poli, béton rugueux. ${ }^{49}$ Le sculpteur, dans le cadre des espaces intérieurs, parvient à une saturation visuelle, apportant ainsi animation et dynamisme au hall. Le mur devient dès lors une surface expressive mais avec, à chaque fois, le souci constant de son intégration totale au bâti. Ce dernier point le rapproche des conceptions artistiques développées par P. Sabatier et les artistes du groupe le «Mur vivant ». Au final le décor du hall, véritable œuvre in situ, se veut presque plus contemporain que l'architecture extérieure de l'édifice.

D. Morog était déjà connu pour avoir réalisé des panneaux en béton moulé pour plusieurs bâtiments du campus universitaire de la Doua à Villeurbanne ainsi que pour différents édifices dans le quartier de la Part-Dieu à Lyon. Mais si son travail semble davantage connu en Rhône-Alpes, sa carrière n'en est pas moins nationale. Il est possible d'observer une de ses œuvres pour un mur de la cafétéria de l'ancien théâtre de $\mathrm{Mâ} \mathrm{on}^{50}$, ainsi que dans de nombreux autres bâtiments (île-de-France, PACA, etc.). Ses créations témoignent du goût pour l'animation des surfaces murales, tant intérieures qu'extérieures, grâce à des panneaux en béton moulés en moyen et bas-relief. Les décennies 1960, 1970 et 1980 sont effectivement une période faste pour ce type de décor en béton architectonique ${ }^{51}$. Dans plusieurs immeubles d'habitat collectif (social et privé), les rez-de-chaussée reçoivent un parement en béton sculpté avec généralement des formes géométriques. De 
même, les bâtiments abritant des collectivités territoriales ou des services publics construits à cette époque donnent souvent aux artistes l'occasion de manifester cette nouvelle approche du mur en tant que surface vivante et animée. Ce succès du béton moulé n'est pas propre à la France et il est possible de parler d'un phénomène international ${ }^{52}$. Les panneaux du hall de l'hôtel de région constituent un bon témoignage de l'engouement de l'époque pour le béton architectonique et les recherches menées sur ce matériau par les artistes et les architectes. Montrer ses qualités plastiques, sa capacité d'adaptation à n'importe quelle forme ainsi que son potentiel esthétique, tel semblait être leur objectif.

\section{Michel Boyer : un ameublement de qualité}

R.-M. Barade et son associé vont faire appel à un troisième artiste en s'attachant les services d'un architecte d'intérieur pour concevoir l'ameublement et la décoration. Ils désirent en effet que les locaux reçoivent un « équipement tout particulier, adapté aux formes et à la destination des lieux $\|^{53}$. Dans l'esprit des architectes, cette volonté prolonge, pour l'intérieur du bâtiment, le souhait de réaliser un édifice de prestige. Ils proposent trois artistes et c'est finalement Michel Boyer qui est préféré à Joseph-André Motte et Georges Ferran ${ }^{54}$. M. Boyer (1935-2011) est alors au sommet de sa renommée. Cet ancien étudiant de l'École Nationale Supérieure des Beaux-Arts, puis de l'École Nationale Supérieure des Arts Décoratifs, travaille au sein de l'agence de Pierre Dufau en 1960, avant de créer sa propre agence en 1968, année où il conçoit l'aménagement de la banque Rothschild (Paris, rue Laffitte) qui lui ouvre les portes du succès. Suivent alors plusieurs réalisations, principalement pour des grandes entreprises ${ }^{55}$ ou pour les pouvoirs publics ${ }^{56}$. Il s'agit généralement de sites où se mêlent espaces de travail et de représentation. Or c'est précisément ce principe qui gouverne la réalisation du futur hôtel de région: un bâtiment qui se doit d'être fonctionnel mais où la mise en scène de l'espace, tant externe qu'interne, doit marquer le citoyen grâce au travail conjoint des artistes.

M. Boyer est à la fois architecte d'intérieur et designer, pratique courante à l'époque, ce qui se traduit dans l'aménagement de l'hôtel de région. Il associe différents éléments d'éditeurs à la mode à du mobilier qu'il a dessinés7, dans un ensemble où prédomine le minéral, en écho avec les matériaux utilisés en parement sur les façades extérieures. Ainsi, la pierre de Comblanchien est-elle utilisée pour les murs de la galerie de liaison, pour ceux du second hall (le bar) et pour les bacs à fleurs tandis que pour le hall d'accueil, les panneaux de D. Morog reprennent également la couleur de la roche. Pour contrecarrer la dominante grise des murs, le choix du designer en matière de meubles se porte vers des teintes plus chaudes, avec une prédilection pour le cuir havane. Cette couleur est d'ailleurs celle des fauteuils de la salle des Assemblées, dessinés par M. Boyer et édités par $\mathrm{Knoll}^{58}$, qui fournit également les chaises de cette pièce ${ }^{59}$ (fig. 33). 
Figure 33

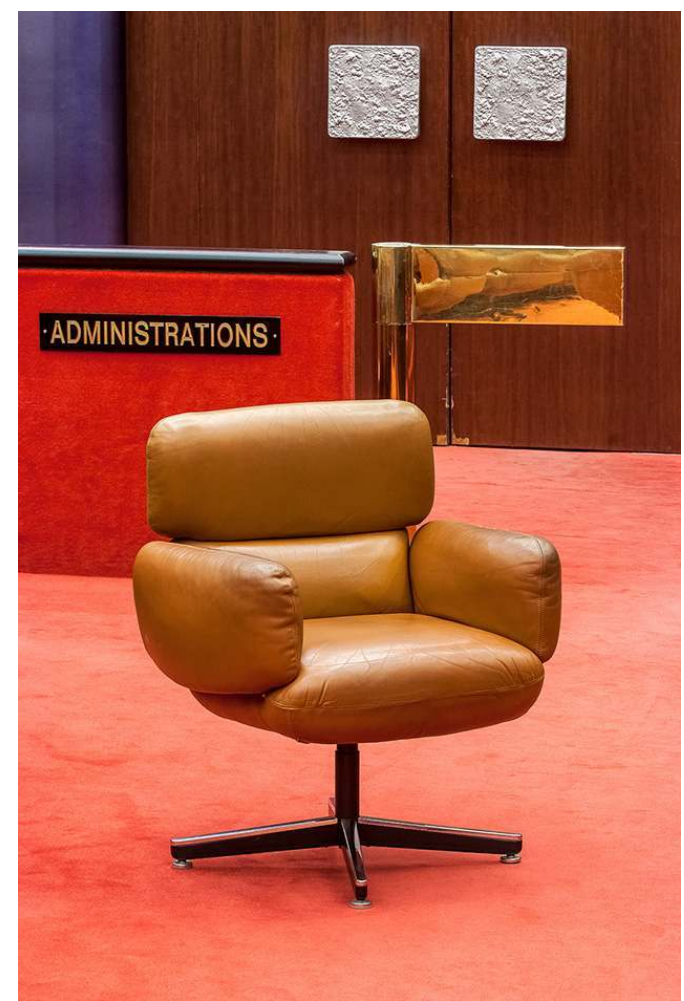

Hôtel de région : fauteuil de la salle des Assemblées, éditeur : Knoll, ca. 1980.

Phot. Pierre-Marie Barbe-Richaud. (c) Service Patrimoine et inventaire, Région Bourgogne, 2014.

Une importance notable est accordée aux luminaires: M. Boyer dessine lui-même les lustres métalliques du hall d'accueil et de la galerie de liaison, où il place également de grands modèles d'une de ses créations les plus célèbres, la lampe Brasilia (fig. 34). 
Figure 34

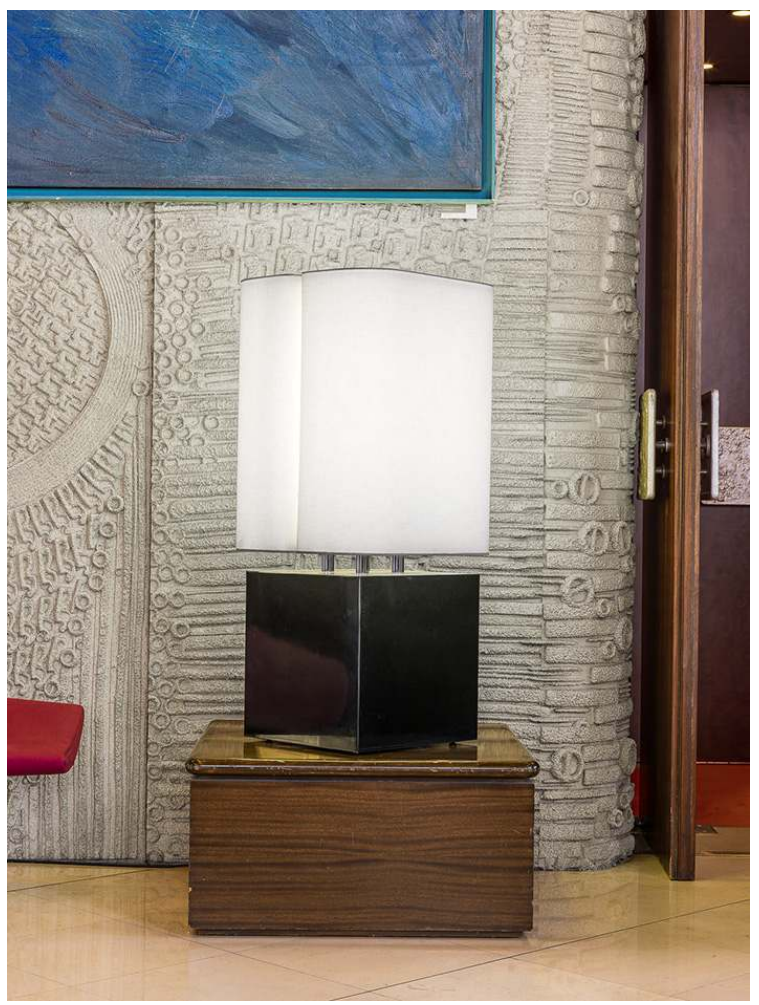

Hôtel de région : hall d'accueil : Michel Boyer, Lampe Brasilia.

Phot. Pierre-Marie Barbe-Richaud. (c) Service Patrimoine et inventaire, Région Bourgogne, 2014

Quant au hall du bar, la lumière y joue aussi un rôle de mise en ambiance avec de nombreuses lampes disposées sur les rebords des jardinières ${ }^{60}$ (fig. 35). Les chauffeuses commandées chez Mobilier International et placées dans le hall, espace moins officiel et davantage dédié à la détente, sont en textile et dans des couleurs plus soutenues. Finalement, après plusieurs étapes de consultation, et en lien avec la commission départementale chargée de l'examen des offres faites pour la fourniture du mobilier, l'architecte d'intérieur fait appel à différentes maisons d'édition dont les principales sont Knoll, Velma, Mobilier International, Strafor et Rouvre ${ }^{61}$ (fig. 36). Il demeure, d'une manière générale, fidèle à son style, privilégiant les associations de bois noble et de métal ; sa seule réelle contrainte étant peut-être de ne pas avoir pu choisir lui-même les deux autres artistes associés à la décoration de l'édifice. 


\section{Figure 35}

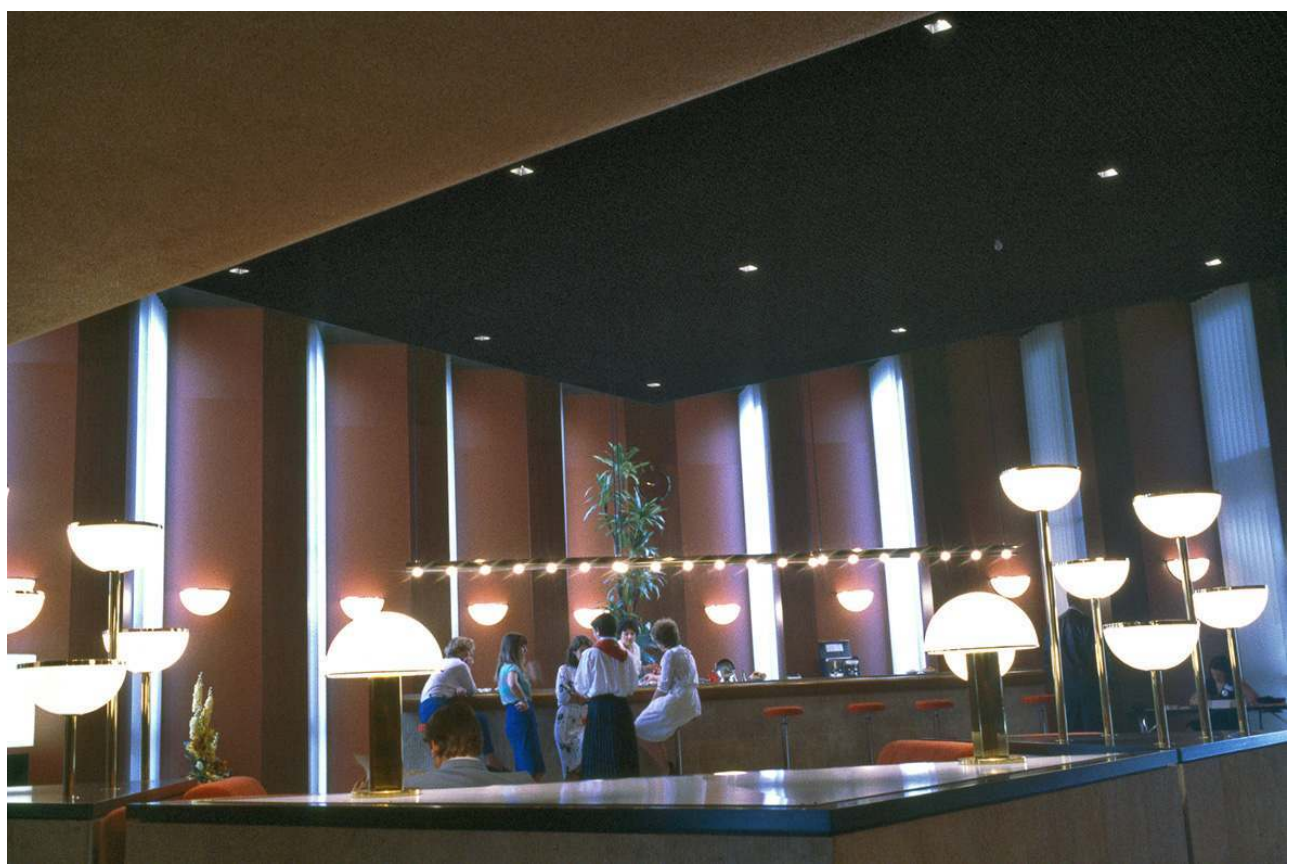

Hôtel de région : hall du bar, ca. 1990-2000.

Repro. Pierre-Marie Barbe-Richaud. Direction de la communication, Région Bourgogne. () Service Patrimoine et inventaire, Région Bourgogne, 2014

\section{Figure 36}

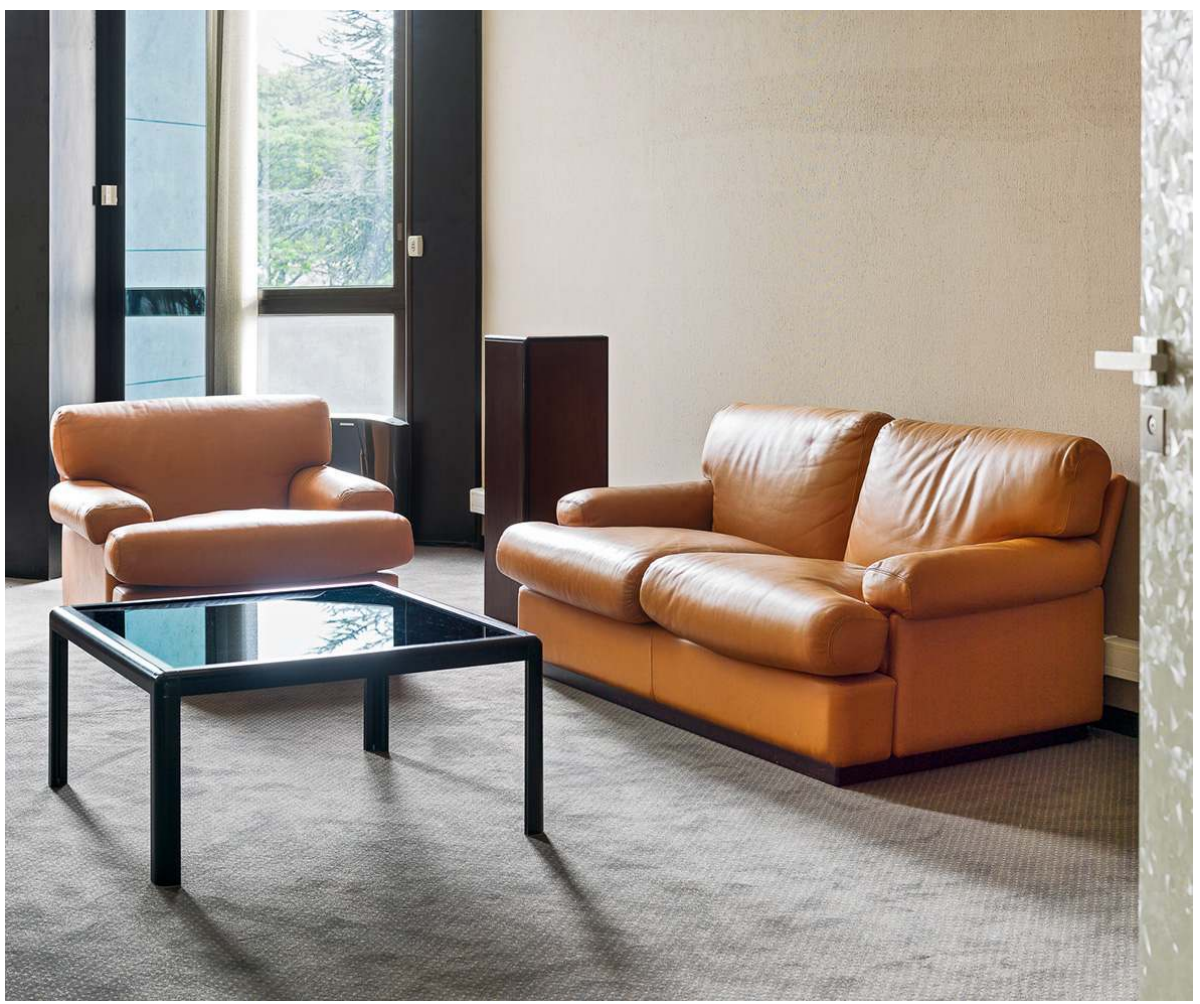

Hôtel de région : mobilier pour les bureaux du premier étage : canapé et fauteuil, éditeur : Cassina, ca 1980.

Phot. Pierre-Marie Barbe-Richaud. (C) Service Patrimoine et inventaire, Région Bourgogne, 2014 
travail de M. Boyer s'inscrit pleinement dans le renouveau du design en France pendant les Trente Glorieuses. Ce chantier illustre bien l'importance des commandes suscitées par les collectivités publiques dans l'élan en faveur du mobilier. L'ameublement des nouvelles institutions que sont les EPR va de pair avec celui des villes nouvelles et de leurs administrations. En effet, de nouvelles collectivités et préfectures sont créées suite à la réorganisation de la région parisienne à partir de 1964. Parallèlement aux vastes programmes architecturaux qui en résultent, les créateurs de mobilier saisissent cette occasion pour diffuser leurs nouvelles gammes destinées aux espaces de bureau. «Des maisons comme Mobilier International, Formes Nouvelles, Meubles et fonction ou Knoll, qui diffusent le mobilier des créateurs étrangers, sont largement sollicitées. Ces chantiers d'importance donnent lieu autant à l'achat en nombre de mobilier courant qu'à la création de "mobilier de prestige" $»^{62}$. M. Boyer et R.-M. Barade souhaitent tout deux parvenir à une certaine mise en scène - voire une véritable scénographie - de l'espace interne, grâce à un ameublement de qualité, considéré comme une valeur ajoutée et associé aux créations plastiques des autres artistes. Somme toute, le parti-pris dominant n'est pas réellement gouverné par des principes rationnels ou fonctionnalistes mais plutôt par ceux de confort, d'aisance et de prestige.

Lors de l'inauguration, un article du quotidien local Le Bien Public insiste d'ailleurs sur l'aménagement luxueux du rez-de-chaussée et du premier étage, notamment son mobilier, où le cuir « règne partout au domaine des élus jusque dans les canapés qui équipent les bureaux $»^{63}$. Le journaliste pointe également du doigt la disparité avec les équipements plus simples et moins somptueux des bureaux des agents. Néanmoins, ce faste se retrouve également dans plusieurs hôtels de région construits entre les années 1970 et 1980. L'ampleur de certains halls permet ainsi de marquer les esprits lors d'une arrivée dans le bâtiment (comme celui de la région Aquitaine ou celui de la région Midi-Pyrénées, véritable atrium sur plusieurs niveaux) et la salle des Assemblées est l'espace de prédilection pour les œuvres d'art plastique ou les éléments de design (une impressionnante sculpture murale de Maurice Calka pour le Centre, une peinture de Jacques Griesmer en Lorraine et des vitraux en dalles de verre ainsi que des lustres de Claude Parent en PACA).

Cependant l'importance accordée au décor et à l'ameublement pour l'hôtel de région de la Bourgogne et ceux de la première génération n'est pas une nouveauté pour les lieux de pouvoir de la République. Elle ne fait que s'inscrire dans une tradition réinterprétée selon les modes décoratives de l'époque où les artistes participent pleinement à une mise en scène fastueuse de ces bâtiments qui s'observe dès la fin de la décennie 1960 avec la réalisation des nouvelles préfectures d'île-de-France et, plus anciennement, avec les hôtels de ville sous la III ${ }^{\mathrm{e}}$ République.

61 Néanmoins, le chantier de l'hôtel de région conserve une certaine modestie malgré l'ampleur des travaux réalisés. On notera que la décennie 1970 voit la fin de « la capacité des décorateurs français à imaginer avec brio le mobilier des nouveaux grands équipements publics. Cette production est le dernier témoignage d'une modernité fière d'elle-même $»^{64}$. En outre, cet attachement à parer le nouvel immeuble d'une certaine somptuosité moderniste va susciter quelques critiques. Comme dit précédemment, la presse locale s'amuse effectivement à souligner, après l'inauguration du 5 juillet 1980, que la richesse du décor et du mobilier a pu «quelque peu choquer nombre de visiteurs» mais que «ce luxe ne tient guère qu'à un étage, les fonctionnaires de la Mission n'ayant pas droit à l'épaisse moquette et aux fauteuils de cuir $»^{65}$. Grâce aux archives et aux 
éléments d'origine demeurés sur place, l'étude de l'ensemble du mobilier commandé à l'époque tend à confirmer ces propos (fig. 37, fig. 38). Le dessein des auteurs du bâtiment était bel et bien d'en faire une réalisation prestigieuse. Cependant, si ces meubles, représentatifs de la décennie 1970, possèdent aujourd'hui une valeur élevée sur le marché de l'art et du design, il faut rappeler que dans leur grande majorité, ce sont des objets de série, commandés sur catalogue : seuls quelques-uns ont été conçus spécialement pour le nouveau bâtiment. Or, cette pratique de commande sur catalogue est finalement strictement identique à celle observée de nos jours.

Figure 37

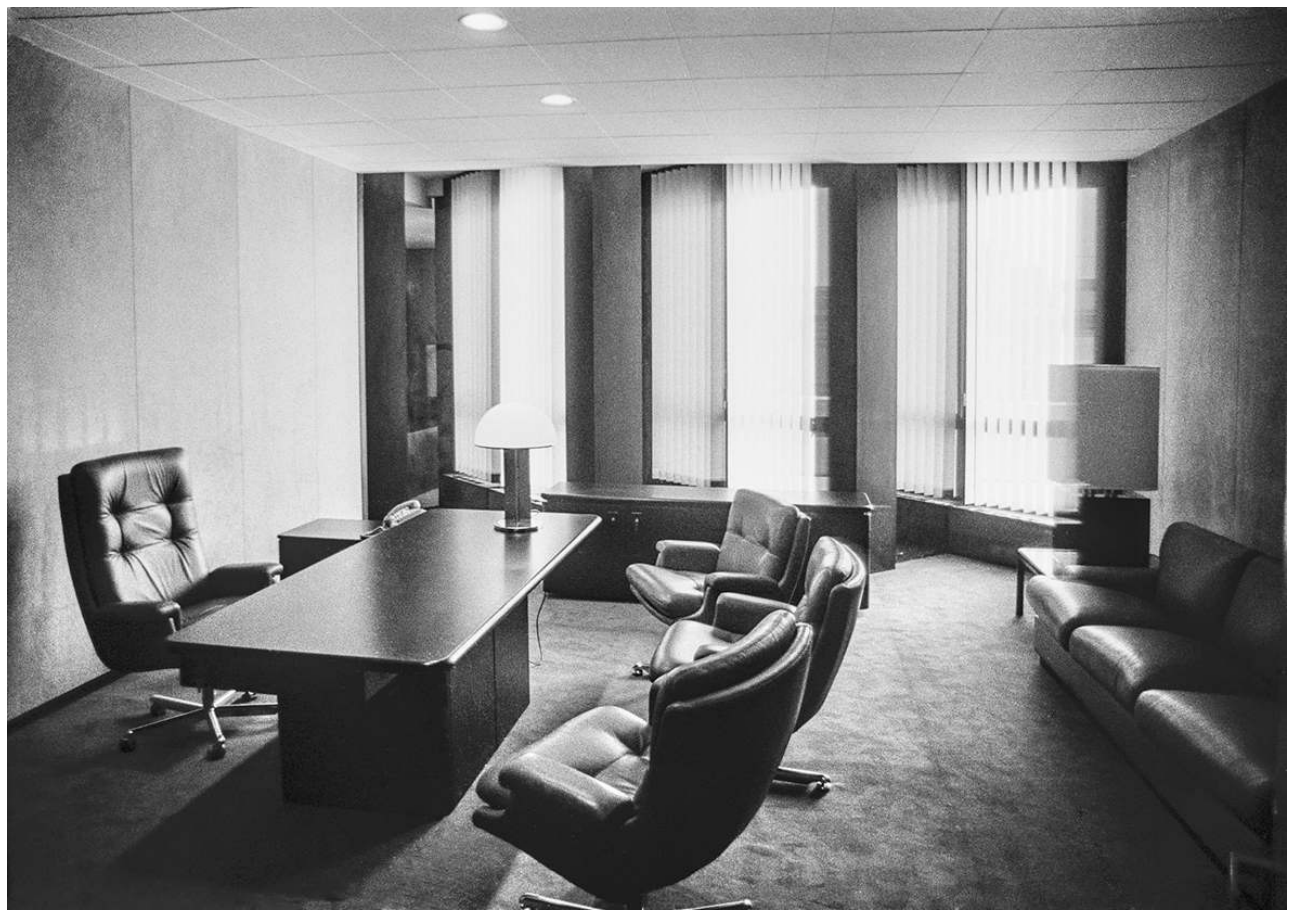

Hôtel de région : bureau du premier étage, photographie ancienne, ca. 1980.

Repro. Pierre-Marie Barbe-Richaud. (c) Archives Le Bien Public. 
Figure 38

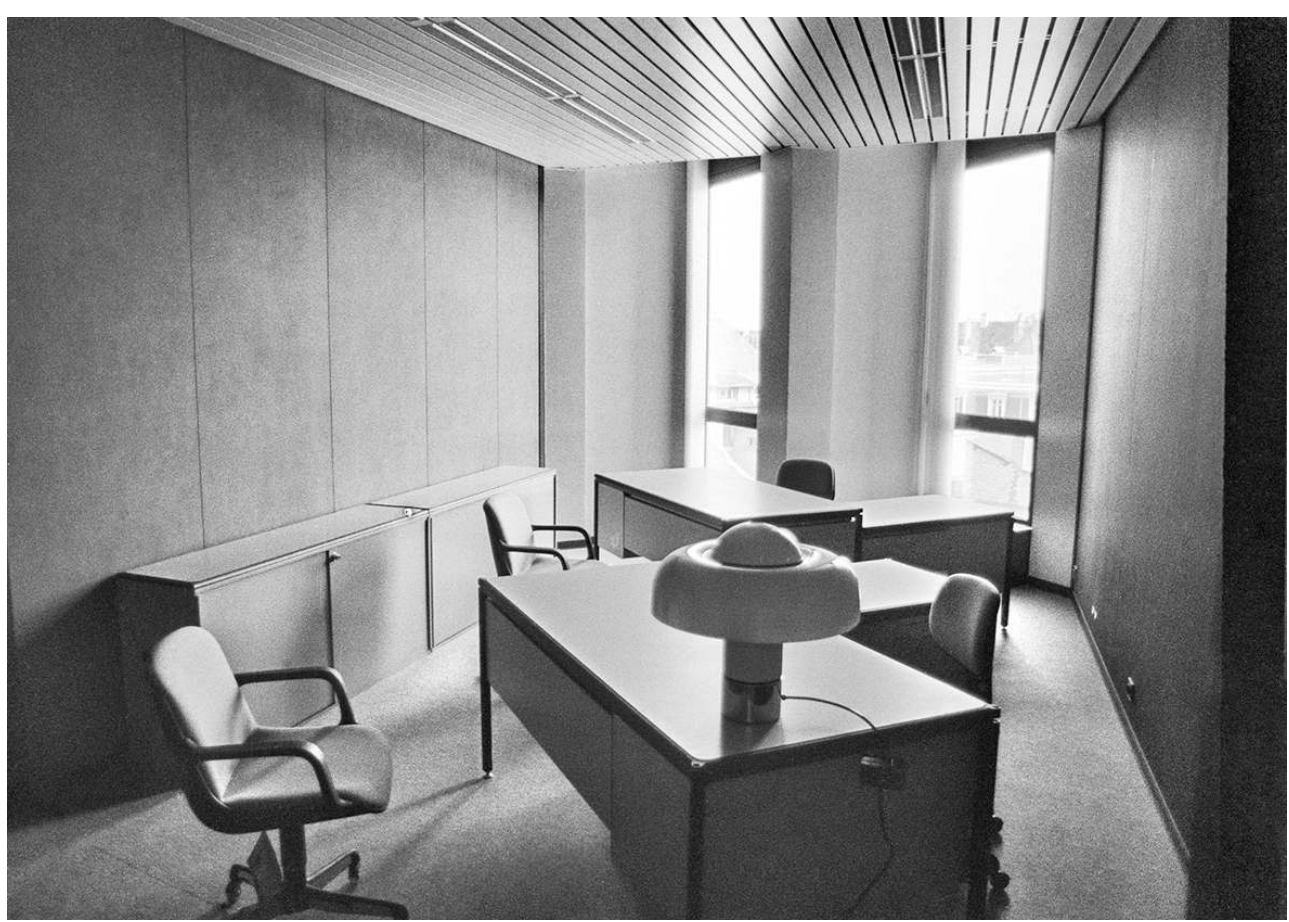

Hôtel de région : bureau du deuxième étage, photographie ancienne, ca. 1980

Repro. Pierre-Marie Barbe-Richaud. (c) Archives Le Bien Public.

\section{Conclusion}

En définitive, ce qui caractérise l'architecture, intérieure et extérieure de l'hôtel de la région Bourgogne est bien d'être représentative d'une période de transition dans l'architecture des administrations. Il se singularise des constructions environnantes par une tentative de monumentalité mais ne peut rivaliser avec les super-structures modernistes davantage propres à l'esprit des années 1960 (préfecture des Hauts-de-Seine et du Val-d'Oise, hôtel de ville de Créteil, etc.). Les contraintes patrimoniales et l'évolution du goût en matière d'architecture contemporaine entraînent une forme d'incertitude. L'édifice paraît osciller entre deux époques, comme une transition entre une architecture moderniste qui voudrait affirmer le rôle de la nouvelle institution et un courant plus postmoderne qui le situe dans l'espace de la cité. Cet essai d'une insertion plus respectueuse de l'environnement bâti illustre le glissement qui s'opère depuis quelques années déjà en France vers ce que l'on qualifie parfois d'architecture d'accompagnement.

De même, les créations plastiques pour la décoration intérieure reflètent une réelle volonté d'offrir un cadre de prestige à la nouvelle institution. Sans doute est-il temps de les étudier comme un patrimoine à part entière. Les salles des assemblées de plusieurs hôtels de région ont ainsi conservé, pour certaines, leur ameublement et leur décor d'origine ${ }^{66}$.

64 Cette réflexion sur l'aménagement interne est également emblématique de la place accordée alors au décor et à l'ornement. Une étude comparative sur les différentes générations d'hôtels de région, mais aussi de département et d'EPCI, permettrait, outre 
une mise en lumière de cette typologie architecturale encore trop méconnue, d'observer quelles sont ses caractéristiques d'une époque à l'autre.

\section{NOTES}

1. - Le conseil régional, et avant lui, l'Établissement Public Régional (EPR), occupait néanmoins le bâtiment depuis sa construction. Suite à la réforme territoriale initiée par la loi du 16 janvier 2015, et après la fusion des conseils régionaux de Bourgogne et de Franche-Comté, l'immeuble dijonnais est devenu le siège des assemblées de la nouvelle collectivité, l'hôtel de région « officiel » étant celui de Besançon.

2. - Archives départementales de la Côte-d'Or, fonds Roger-Martin Barade, $32 \mathrm{~J}$, voir le site : www.archives.cotedor.fr [consulté le 21/12/2017].

3. - Vestige de l'ancienne dépendance de l'abbaye de Clairvaux à Dijon, le cellier éponyme date du $\mathrm{XIII}^{\mathrm{e}}$ siècle et a été classé au titre des Monuments historiques en 1915. L'édifice consiste en une vaste construction massive de plan rectangulaire de $33 \mathrm{~m}$ de long sur $13 \mathrm{~m}$ de large avec le logis, dit abbatial, mitoyen au nord. Le tout forme un ensemble en L. Les façades orientale et occidentale présentent la même architecture, à savoir des murs en moyen appareil renforcés par des contreforts qui forment une série d'arcades plein-cintre. Le bâtiment accueille actuellement des manifestations culturelles.

4. - BROCHARD, Antoine. "Les Hôtels de région. Architectures républicaines à l'aune de la décentralisation ». Dans MONNIER, Gérard, COHEN, Évelyne (dir.). La République et ses symboles : un territoire de signes. Paris : Publications de la Sorbonne, 2013, p. 347-359.

5. - On citera à titre d'exemple les régions Basse-Normandie et Haute-Normandie installées respectivement depuis 1986 dans l'abbaye aux Dames de Caen et dans l'ancienne caserne Jeanned'Arc à Rouen, la région Champagne-Ardenne dans le Grand Séminaire de Châlons-enChampagne, la région Franche-Comté dans l'ancien hôtel de Grammont, l'Assemblée de Corse dans le Grand Hôtel en 1983 à Ajaccio ou encore la région Lorraine, installée dans l'abbaye SaintClément à Metz depuis 1984.

6. - Dans son article - un des premiers sur le sujet - la revue Le Moniteur donne comme sous-titre à une partie de son texte "Les régions bâtisseuses : le sud pionnier » (« Les régions dans leurs murs ", Le Moniteur, 18 juillet 1986, p. 44-53). À titre d'exemple on citera les régions Aquitaine, Bourgogne, Centre, Limousin, Midi-Pyrénées, Languedoc-Roussillon, Pays de la Loire et PACA. La région Poitou-Charentes réalise un compromis en mêlant rénovation et création nouvelle sur le site d'une ancienne institution religieuse, en plein centre-ville de Poitiers.

7. - On donnera comme exemple les régions Alsace, île-de-France, Nord-Pas-de-Calais, Picardie et Rhône-Alpes.

8. - Ancien nom des CESER.

9. - Compte rendu de la réunion pour la construction d'un immeuble pour l'EPR de Bourgogne du 6 janvier 1975, Archives départementales de la Côte-d'Or, 32 J 53.

10. - Roger-Martin Barade (1908-1987) : né à Bègles (Gironde), il entre à l'École des Beaux-Arts de Bordeaux en 1924 puis à l'École Nationale Supérieure des Beaux-Arts de Paris en 1928 ; il obtient le titre d'architecte DPLG en 1933 et s'installe à Dijon en 1934. Il réalise notamment le pavillon de Bourgogne, Franche-Comté et Pays de l'Ain pour l'Exposition Internationale de Paris en 1937. En 1941, il est nommé architecte départemental de la Côte-d'Or, tout en conservant une activité 
libérale. Sa carrière se poursuit avec les travaux pour les Hospices civils à partir de 1943 et la création du nouveau campus universitaire de Dijon en 1952. Ces deux vastes projets se poursuivent jusque dans les années 1970 avec entre-temps plusieurs bâtiments pour l'Université de Metz (1960-1970), ainsi que différentes constructions (projets privés et publics) à Dijon, Beaune, Semur, Saint-Apollinaire, etc. L'hôtel de région fait partie de la dernière série de grands travaux de l'architecte qui s'achève avec l'aménagement des nouveaux locaux du conseil général de la Côte-d'Or en 1982.

11. - François Ruault (1927-2012) : architecte DPLG, François Ruault collabore avec Roger-Martin Barade dès le milieu des années 1950 mais la création de l'agence Barade-Ruault date de 1975, lorsque débutent les études pour le nouvel immeuble départemental (futur hôtel de région). Il succède à R.-M. Barade, parti en retraite, comme architecte du département de la Côte-d'Or, de 1984 à 1989, et cesse son activité en 1993.

12. - Comptes rendus des réunions du 12 juin 1975 et du 5 août 1975, Archives départementales de la Côte-d'Or, $32 \mathrm{~J} 53$.

13. - Compte rendu de la réunion du 12 juin 1975 (Archives départementales de la Côte-d'Or, $32 \mathrm{~J}$ 53). Ces propos sont repris par l'ingénieur en chef directeur du Plan de la mairie de Dijon dans les notes qu'il adresse au maire adjoint à l'urbanisme entre 1975 et 1976 (Archives municipales de Dijon, 11031 W 267).

14. - Lors de la création du ministère d'État des Affaires culturelles en 1959, la CSMH est composée de quatre sections (Objets immobiliers, Objets mobiliers, Collections scientifiques et Orgues). Les prémices d'une section des Abords apparaissent avec la loi du 25 février 1943 mais il fallut attendre le décret du 21 mai 1964 pour que soit créée la section des Abords.

15. - Procès-verbal de la séance du $1^{\mathrm{er}}$ octobre 1975 de la section des Abords des immeubles classés et inscrits (Médiathèque du patrimoine et de l'architecture, 0080/059).

16. - SITTE, Camillo. L'Art de bâtir les villes. L'urbanisme selon ses fondements artistiques. Paris : Éd. du Seuil, 1996, (éd. originale : Der Städtebau nach seinen künsterlischen Grundsätzen, Vienne, Graeser, 1889).

17. - CHOAY, Françoise. «Pour une nouvelle lecture de Camillo Sitte». Communications, $\mathrm{n}^{\circ} 27$, 1977, p. 112-121.

18. - LE CORBUSIER. La Charte d'Athènes. Paris : Éd. de Minuit, 1971, p. 91, (éd. originale, Paris : Plon, 1943).

19. - La Charte d'Athènes pour la Restauration des Monuments historiques, adoptée lors du premier congrès international des architectes et techniciens des monuments historiques, Athènes, 1931, voir sur le site : www.icomos.org [consulté le 21/12/2017].

20. - Dans le cadre de la loi relative à la liberté de la création, à l'architecture et au patrimoine (LCAP) du 7 juillet 2016, la politique en matière d'abords de monuments historiques a quelque peu évolué avec davantage de liens avec les documents d'urbanisme locaux. Désormais, il incombe au préfet, sur proposition de l'ABF, après enquête publique, consultation du propriétaire et accord de l'autorité compétente en matière de document d'urbanisme, de délimiter le périmètre de la protection au titre des abords. Par défaut, «la protection s'applique alors à tout immeuble, bâti ou non bâti, visible du monument historique ou visible en même temps que lui et situé à moins de 500 mètres de celui-ci » (Code du patrimoine : L.621-30).

21. - LAURENT, Xavier. Grandeur et misère du patrimoine: d'André Malraux à Jacques Duhamel, 1959-1973. Paris : École des chartes/Comité d'histoire du ministère de la Culture, 2003, p. 148.

22. - BACKOUCHE, Isabelle. Aménager la ville: les centres urbains français entre conservation et rénovation, de 1943 à nos jours. Paris : A. Colin, 2013, p. 77.

23. - Nommé directeur de l'Architecture en 1963, Max Querrien a notamment la responsabilité des services des Monuments historiques et des sites ainsi que les Bâtiments civils.

24. - BACKOUCHE, Isabelle. Op. cit., p. 235.

25. - LAURENT, Xavier. Op. cit., p. 157. 
26. - Sur ce sujet, voir : MIGAYROU, Frédéric (dir.). La Tendenza : architectures italiennes, 1955-1985. Paris : Centre Pompidou, 2012 ; COHEN, Jean-Louis. La Coupure entre architectes et intellectuels, ou les enseignements de l'italophilie [1984]. Paris: Mardaga, 2015 ; MAZZONI, Cristiana. La Tendenza. Une avant-garde italienne, 1950-1980. Marseille : Parenthèses, 2013.

27. - Henry Bernard lui conseille de conserver le plan de distribution interne, mais il trouve que les premières esquisses de façades présentées en CA sont ternes : «[...] il faut à la fois être simple et bien affirmer le caractère, bref faire de l'Architecture. [...] Il faut que le passant sache que, derrière ce mur noble, siège son assemblée régionale. [...] Je pense qu'il faut affirmer le caractère politique de ce bâtiment... ». Annotations sur plans d'Henry Bernard, adressées à Roger-Martin Barade (Archives départementales de la Côte-d'Or, $32 \mathrm{~J}$ 50).

28. - Voir ci-après pour plus d'informations sur cet artiste.

29. - Il a conservé cette fonction, le bureau du président du Conseil régional et ceux du cabinet y étant toujours situés.

30. - On notera tout de même, comme l'a remarqué la presse locale («La région dans ses meubles». Le Bien Public, 6 juillet 1980) que si les bureaux disposent d'une source de lumière directe, leur profondeur impose quand même un recours à l'éclairage électrique.

31. - «Place-parvis: place attenante formant dégagement devant la façade antérieure d'un édifice important ou remarquable » (GAUTHIEZ, Bernard. Espace urbain. Vocabulaire et morphologie. Paris : Éditions du patrimoine, coll. « Principes d'analyse scientifique », 2003, p. 135).

32. - R.-M. Barade, Devis descriptif, 16 avril 1976, p. 6 (Archives départementales de la Côte-d'Or, $32 \mathrm{~J} 51)$.

33. - Ibid.

34. - Ibid.

35. - Sans doute faut-il comprendre la recommandation d'Henry Bernard comme une incitation à réaliser un édifice qui s'impose visuellement et où le travail de composition est pleinement perceptible tant dans l'agencement des volumes généraux que des lignes des façades.

36. - D'ORGEVAL, Domitille. Pierre Sabatier Sculpteur. Paris : Norma, 2011, p. 76.

37. - Roger-Martin Barade dirige le chantier entre 1974 et 1976.

38. - Roger-Martin Barade, Devis descriptif, 16 avril 1976, p. 6 (Archives départementales de la Côte-d'Or, 32 J 51).

39. - Archives privées P. Sabatier.

40. - Lettre de Roger-Martin Barade à Pierre Sabatier du 29 novembre 1976 (archives privées Pierre Sabatier).

41. - Dans un premier temps, Pierre Sabatier avait opté pour l'acier, mais l'aluminium s'est finalement imposé car plus léger et plus malléable.

42. - D'ORGEVAL, Domitille. Op. cit., p. 100.

43. - Pierre Sabatier, devis descriptif du 27 novembre 1978 (Archives départementales de la Côted'Or, $32 \mathrm{~J} 82$ ).

44. - Un article lui est consacré dans le numéro 453 de juillet 1976 de la Revue de l'aluminium, où son souci d'unité est salué par l'auteur.

45. - Courrier de Roger-Martin Barade à Pierre Sabatier en date du 7 janvier 1980 (Archives privées P. Sabatier).

46. - Denis Morog est le nom d'artiste de Jean-Paul Delhumeau (1922-2003). Formé à l'École des Beaux-Arts de Paris, il commença par être graveur puis développa une technique spécifique pour réaliser ses panneaux en béton sculpté.

47. - 32 J 82, Archives départementales de la Côte-d'or.

48. - Le fonds d'atelier privé de l'artiste ne conserve pas de documents concernant le projet dijonnais.

49. - MOROG, Denis. Le Beau béton. Paris : Éd. du Moniteur, 1981. 
50. - Actuellement centre culturel Louis-Escande. L'édifice, réalisé entre 1973 et 1975, est l'œuvre de l'architecte Robert Levasseur. Il est possible de penser que c'est là que Roger-Martin Barade a découvert le travail de Denis Morog.

51. - Il s'agit du terme utilisé par Roger-Martin Barade pour parler des panneaux de Denis Morog. 52. - JORAY, Marcel. Le Béton dans l'art contemporain. Neuchâtel : Éd. du Griffon, 1987. Cet ouvrage montre bien l'ampleur du mouvement, même s'il ne prétend pas être exhaustif. On peut citer à titre de comparaison le mur-relief de Costantino Nivola à Hartford (Connecticut, 1951) ou encore la structure murale de Otto Herbert Hajak à Bochum (Rhénanie du Nord-Westphalie, 1970-1972). 53. - Courrier de R.-M. Barade au préfet de la Côte-d'Or du 24 octobre 1977 (Archives départementales de la Côte-d'Or, $32 \mathrm{~J}$ 81).

54. - Délibération de la commission départementale, le 28 octobre 1977 (Archives départementales de la Côte-d'Or, $32 \mathrm{~J}$ 81).

55. - JCDecaux, tour Elf de la Défense, l'hôtel PLM de Paris, sièges de Total et Saint-Gobain, plusieurs boutiques pour Dior et Lanvin, etc.

56. - Comme l'ambassade de France à Brasilia en 1974 ou l'hôtel de ville de Créteil (Val-deMarne).

57. - De 1968 à 1980, Michel Boyer possède également la boutique Rouve à Paris, où il commercialise et édite les meubles qu'il dessine.

58. - (Archives départementales de la Côte-d'Or, 32 J 55). Michel Boyer a d'ailleurs repris de manière assez troublante les lignes du modèle créé par Otto Zapf pour Knoll en 1973.

59. - Il s'agit d'un modèle conçu par Max Pearson.

60. - Concernant les bacs-jardinières des deux halls (accueil et bar), Michel Boyer décide de les revêtir elles aussi d'un parement en pierre de Comblanchien afin qu'ils s'harmonisent avec les murs.

61. - Archives départementales de la Côte-d'Or, 32 J 55.

62. - FOREST, Dominique (dir.). Mobi Boom : l'explosion du design en France, 1945-1975. Cat. exp., Paris, musée des Arts décoratifs, 22 septembre 2010-2 janvier 2011. Paris : Arts décoratifs, 2010, p. 166.

63. - « La région dans ses meubles ». Le Bien Public, 6 juillet 1980.

64. - FOREST, Dominique (dir.). Op. cit., p. 61.

65. - « La région dans ses meubles ». Art. cit.

66. - Une première recherche nous permet de proposer les trois salles d'assemblées les plus anciennes ayant conservé leur aménagement d'origine. À savoir, dans l'ordre chronologique : Picardie (1977), Bourgogne (1977-1980), Centre (1980-1986).

\section{RÉSUMÉS}

L'hôtel de région de Bourgogne a été construit entre 1978 et 1980 en limite du secteur sauvegardé $\mathrm{du}$ Vieux-Dijon. L'histoire de son édification témoigne des enjeux de l'architecture de l'administration. L'objet de cet article se concentre sur « les contraintes patrimoniales » qui ont imposé à l'architecte de revoir son projet d'origine pour l'harmoniser avec le bâti environnant. Les conditions d'édification du bâtiment sont représentatives de l'évolution de la place accordée à l'architecture contemporaine dans un site ancien en France au cours de cette période. Les architectes Roger-Martin Barade et François Ruault sont parvenus à réaliser un édifice imposant, représentatif d'une époque de transition entre les années 1970 et 1980 . En outre, l'étude a 
également permis de redécouvrir toute l'attention portée, à l'époque, aux éléments de décoration intérieure. Plusieurs artistes renommés (Denis Morog, Pierre Sabatier et Michel Boyer) ont été sollicités afin d'apporter une réelle valeur ajoutée au bâtiment grâce à leurs œuvres qui se caractérisent par une réflexion sur l'intégration à l'architecture.

This paper deals with history, architecture and decoration of the Burgundy 'hotel de region', its administrative and government centre, built between 1978 and 1980. The architects RogerMartin Barade and François Ruault succeeded in creating a building which is representative of the evolution of the place of contemporary architecture in ancient and heritage sites in France during the 1970s, and of tastes where decoration, furniture and interior fittings are concerned in the realm of the French administration during the same decade. This study also focuses on the employment of some celebrated artists (Pierre Sabatier, Denis Morog and Michel Boyer) whose works were characterised by reflection on how to integrate art into architecture. The architecture of the building as a whole reflects the different evolutions of the project in order to take into account heritage conservation requirements.

\section{INDEX}

Keywords : heritage architect, contemporary architecture, architecture of the second half of the twentieth century, administration, Burgundy, Historic Monuments Commission, public architecture, post-modernism, modernity, furniture sets, accompanying architecture, hôtel de région, regional council, Denis Morog, Roger-Martin Barade, Pierre Sabatier, Michel Boyer, heritage environment commission

Mots-clés : architecte des bâtiments de France, architecture contemporaine, architecture de la seconde moitié du XXe siècle, administration, Bourgogne, Commission des Monuments historiques, architecture publique, post-modernisme, modernité, ensemble mobilier, architecture d'accompagnement, Hôtel de région, Conseil régional, Denis Morog, Roger-Martin Barade, Pierre Sabatier, Michel Boyer, Commission des Abords

\section{AUTEUR}

\section{JULIEN DEFILLON}

Chercheur, région Bourgogne - Franche-Comté, service Inventaire et Patrimoine julien.defillon@bourgognefranchecomte.fr 